\title{
An Expanded Study on the Stock Market Temperature Anomaly
}

\author{
Melanie Cao \\ Schulich School of Business \\ York University \\ 4700 Keele Street \\ Toronto, Ontario \\ Canada, M3J 1P3 \\ mcao@ssb.yorku.ca
}

\author{
Jason Wei \\ Joseph L. Rotman School of Management \\ University of Toronto \\ 105 St. George Street \\ Toronto, Ontario \\ Canada, M5S 3E6 \\ wei@rotman.utoronto.ca
}

Current Version: June 2005

* Both authors are grateful to the Social Sciences and Humanities Research Council of Canada for financial support. They would like to thank conference participants at the 2002 Financial Management Association meeting, the 2002 Northern Finance Association meeting and the 2003 Western Finance Association meeting for helpful discussions and comments. 


\section{An Expanded Study on the Stock Market Temperature Anomaly}

This is a companion paper to our previous study in Cao and Wei (2005) on stock market temperature anomaly for eight international stock markets. The temperature anomaly is characterized by a negative relationship between stock market returns and temperature. This line of work relies on the impact of environmental variables, such as temperature, on mood and behavior changes. In this paper, we expand the sample in Cao and Wei (2005) to include 19 additional financial markets. Our evidence confirms the identified negative relationship for the expanded sample. More importantly, our non-parametric tests, as opposite to the parametric or semi-parametric approaches used by previous related studies, demonstrate that this negative relationship is robust to distributional assumptions. Based on the sub-sample analysis, we find that this negative relationship is stable over time. Furthermore, we consider temperature deviation and demonstrate that this negative relationship is not just a level effect.

Keywords: stock market returns, stock market anomalies, temperature anomaly.

JEL classifications: G14, G10, G15. 
Recently, there are four main studies linking the stock market return anomaly to naturerelated variables such as the amount of sunshine, the length of day light and temperature. ${ }^{1}$ In particular, Saunders (1993) is the first study which examines the relationship between stock market returns and the amount of sunshine. Focusing on the City of New York for the period of 1927 - 1989, Saunders (1993) demonstrates that less cloud cover is associated with higher returns for the DJIA index, the NYSE/AMEX value-weighted index, and the NYSE/AMEX equalweighted index, and the returns on most cloudy days are significantly different from the returns on the least cloudy days. Hirshleifer and Shumway (2003, hereafter HS) confirm these results for 26 international stock markets for the period of $1982-1997$. The common conjecture made by these three authors is that investors' mood is upbeat or optimistic on sunny (or least cloudy) days, which uplifts the stock market returns, and that their pessimistic mood on cloudy days depresses the stock returns.

Kamstra, Kramer and Levi (2003, hereafter KKL) draw a link between stock market returns and the length of day light. By examining the stock returns in the U.S., Canada, U.K. and Germany and a few other countries, they find that lower returns are associated with longer nights. Their explanation rests on the impact of Seasonal Affective Disorder (SAD) on human behavior. Based on the psychological and clinical evidence, the authors conjecture that lower returns are caused by investors who are depressed because of longer nights.

In a recent study in Cao and Wei (2005, hereafter CW), we examine the linkage between temperature and stock returns for the U.S., Canada, Britain, Germany, Sweden, Australia, Japan and Taiwan. We find that stock returns are negatively correlated with temperature. That is, the lower the temperature, the higher the return, and vice versa. This negative correlation is statistically significant. Such a negative relationship still remains even after controlling for the above mentioned sunshine and SAD effects. Similar to Saunders (1993), HS (2003) and KKL (2003), we conjecture that this relationship is attributed to temperature impacts on human behavior. In particular, the psychological literature indicates that very high or very low 
temperatures cause aggression and very high temperature can also induce hysteria and apathy. ${ }^{2}$ Given this psychological finding, we hypothesize that lower temperature is associated with higher stock return due to aggressive risk taking while high temperature can lead to either higher or lower stock returns since both aggression (associated with risk taking) and apathy (associated with risk averting) are possible consequences the net impact on investors' risk taking depends on the trade off between the two.

Apparently, the common feature shared by these studies is this chain of thinking: environmental variables, such as sunshine, length of day light and temperature, affect people's mood which in turn influences people's behavior. Such thinking is motivated and supported by literature on mood and decision-making. For example, Schwarz (1990), and Loewenstein, Weber, Hsee and Welch (2001) provided theories linking mood and feelings to general decision-making, while Etzioni (1988), Romer (2000), and Hanock (2002) established the importance of emotions in economic decision-making. Mehra and Sah (2002) showed theoretically that the emotional state of investors will influence equity prices when investors' subjective parameters such as riskaversion change in response to mood fluctuations.

This line of research has taken its roots in mainstream financial research. As a result, in order to better understand these nature-related stock market anomalies, more studies are needed. The current paper, a sequel study to our previous work (CW 2005), is intended to fulfill this objective. We propose alternative tests and provide additional evidence to support the uncovered stock market temperature anomaly. In particular, we perform the bin test and regression analysis used in CW (2005) for an expanded sample which includes 27 international markets. Moreover, we use alternative tests (including non-parametric methods) to further examine the relationship between temperature and stock returns. Our additional tests and results (using either CW's original sample or an expanded data set) confirm the uncovered stock market temperature anomaly documented in CW (2005). 
The rest of the paper is organized as follows. Section I briefly describes the expanded data set and reports summary statistics of returns and temperatures for the 27 international stock markets and locations. Section II applies the bin test and regression analysis developed by $\mathrm{CW}$ (2005) to the expanded data set, and demonstrates that the uncovered negative relationship between temperature and stock returns remains for a much wider range of financial markets. Section III proposes alternative testing methods to further examine the temperature anomaly. Our new evidence shows that the uncovered temperature anomaly is robust to distributional assumptions and is not just a level effect. Section IV concludes the paper. Figures and tables are collected at the end of the paper.

\section{Data}

As stated earlier, the current paper is a companion work to CW (2005). To be consistent, we utilize the original data which includes nine international stock indices, covering eight financial markets in the United States, Canada, Britain, Germany, Sweden, Australia, Japan and Taiwan. In addition, we expand the data set to include other 19 non-overlapping financial markets studied by either HS (2003) or KKL (2003). As noted in CW (2005), the stock index data are retrieved from Datastream while the temperature data are purchased from the Earth Satellite Corporation (EarthSat). ${ }^{3}$ Following HS (2003), the temperature data for the additional 19 locations are obtained from the National Climate Data Center (NCDC). The corresponding stock markets are either represented by the Datastream Global Indices, or by local market indices which cover a longer sample period.

The temperature variable is the average of the daily maximum and minimum temperatures, which we simply refer to as "daily temperature". For a given sample period, there are always more observations for temperature than for returns since the latter can only be observed for trading days. To perform empirical analysis, the return and temperature series have to be matched. That is, temperature observations for holidays and weekends need to be removed. 
After matching for the eight financial markets in CW (2005), Sweden has the smallest sample size of 3129 while the U.S. has the largest sample size of 9442 . This data set is called "the full sample" set in CW (2005) since they cover each market's longest possible period. To facilitate seemingly unrelated regressions and to ensure comparability of results, an "equal-sized sample" is also created in CW (2005) by matching all indices and temperatures across markets within the common sample period of January 2, 1989 to December 31, 1999. The equal-sized sample has 2252 observations for each market.

As for the 19 additional locations, temperature data from the NCDC are limited to the sample period of 1982 to 1997 . Also, some indices have starting dates later than 1982. In contrast to the temperature data obtained from EarthSat, the temperature data from the NCDC are typically incomplete (i.e., with many missing observations) and sometimes contain errors (e.g., some temperatures are higher than 300 degrees Celsius). After deleting the obvious erroneous observations for each location, we end up with the number of observations as shown in Table 1. The corresponding "equal-sized sample" for the 27 international markets overlaps from 1989 to 1997 with total observations of 1509 for each location.

Table 1 presents city locations, countries/state, sample periods and summary statistics of daily returns and daily temperatures. For daily returns, the mean ranges from $0.005 \%$ for Japan to $0.662 \%$ for Brazil. The standard deviation varies across indices, with Argentina being the most volatile market at $3.775 \%$ and the CRSP equal-weighted index the least volatile at $0.68 \%$. The largest single-day loss was $-28.71 \%$, experienced in Australia during the October 1987 crash. The largest single-day gain was $26.182 \%$, experienced in Argentina. Most of the index returns exhibit negative skewness and strong kurtosis. ${ }^{4}$

The average temperature ranges from $4.24^{\circ} \mathrm{C}$ in Oslo, Norway to $27.79^{\circ} \mathrm{C}$ in Kuala Lumpur, Malaysia. The standard deviation of daily temperature varies from $2.84^{\circ} \mathrm{C}$ in Rio de Janeiro, Brazil to $10.59^{\circ} \mathrm{C}$ in Toronto, Canada. The lowest temperature was $-34.25^{\circ} \mathrm{C}$ in Helsinki, Finland while the highest temperature was $35.00^{\circ} \mathrm{C}$ in Athens, Greece. For most cities, the 
temperature series reflects a negative skewness, indicating that it is more common to have extremely cold days than extremely hot days. To illustrate the temperature progressions throughout the calendar year, we plot the historical average daily temperature for four cities in Figure 1: New York, London, Sydney and Tokyo. ${ }^{5}$ For cities on the Northern Hemisphere, seasonal temperature changes are similar, though the range of variations can be quite different. Naturally, an opposite pattern is observed for Sydney which is on the Southern Hemisphere. It is clear from Figure 1 that Sydney has the smallest seasonal variation in temperature.

\section{Empirical Results of Bin Tests and Regression Analysis}

In this section, we first briefly recapitulate the two types of tests used in CW (2005). Then we perform these tests (with variations) for the original and the expanded sample to ascertain the relationship between temperature and stock market returns uncovered in CW (2005).

\section{A. Bin Tests}

In our previous study (CW 2005), we use two main tests: the "Bin Test" and the "Regression Analysis". The "Bin Test" is implemented by grouping returns according to temperature ordering and calculating a z-score to assess the statistical difference between returngroups. This test is semi-parametric in nature because of the ordering procedure. In particular, we sort the matched return and temperature data by temperature in ascending order, and then divide the sorted series into sub-groups or bins. For each temperature bin, we compute the mean return and the frequency or percentage of positive returns, then compare the mean returns associated with the lowest bin (i.e., the bin covering the lower spectrum of the temperature range) and the highest bin (i.e., the bin covering the higher spectrum of the temperature range) and determine whether the difference in mean returns is significant. Similar comparisons and tests are done for the percentage of positive returns of the two extreme bins. The purpose of examining the frequency of positive returns is to see if the return difference between bins is driven by outliers. If, 
for example, lower temperature is indeed associated with higher stock returns and vice versa, then we would expect that the higher returns in the low temperature bin are broadly based. In other words, we would expect the percentage of positive returns to be high in the low temperature bin.

The precise testing procedure is as follows. First, we compute the difference between the maximum and minimum of the temperature series. Then, we divide the difference by the number of bins, $\mathrm{k}$ to obtain the temperature range of each bin. That is, $\Delta=\left(\operatorname{Temp}_{\max }-\right.$ Temp $\left._{\min }\right) / \mathrm{k}$. The first bin contains temperatures in the range $\left[\operatorname{Temp}_{\min }, \operatorname{Temp}_{\min }+\Delta\right)$; the second bin contains temperatures in the range $\left[T e m p_{\min }+\Delta, T e m p_{\min }+2 \Delta\right) ; \ldots$ and so on. For example, if the maximum and minimum temperatures are 24 and -3 , respectively, and the number of bins is 3 , then the first bin will contain temperatures ranging from -3 to 6 , the second bin ranging from 6 to 15 , and the third ranging from 15 to 24 .

To determine whether the mean returns associated with the highest temperature bin (i.e., bin k) and the lowest temperature bin (i.e., bin 1) are significantly different, we compute the following $z$ statistic:

$$
z_{-} \text {score }_{k, 1}^{\text {mean }}=\frac{\mu_{k}-\mu_{1}}{\sqrt{\sigma_{k}^{2} / n_{k}+\sigma_{1}^{2} / n_{1}}}
$$

where $\mu_{i}, \sigma_{i}$ and $n_{i}$ stand for the mean return, the standard deviation of return and the number of observations in bin $i(i=1$ or $k)$. A similar $z$ statistic is calculated to determine whether the frequencies of positive returns are significantly different between the two extreme bins:

$$
z_{-} \text {score }_{k, 1}^{\text {frequence }}=\frac{p_{k}-p_{1}}{\sqrt{p_{k}\left(1-p_{k}\right) / n_{k}+p_{1}\left(1-p_{1}\right) / n_{1}}}
$$

where $p_{i}$ stands for the percentage of positive returns in bin $i(i=1$ or $k)$.

It can be argued that the potential heteroscedasticity in the variance estimators used to construct the $\mathrm{z}$ statistic should be largely absent for two reasons. First, the heteroscedasticity in the variance for the frequency of positive daily returns is ruled out because the variable measures a binomial outcome. Second, it is unlikely that the variance for daily percentage returns is 
heteroscedastic because the observations are grouped by temperature, a random exogenous factor. In daily or monthly return time series, heteroscedasticity is often present, as documented by French, Schwert and Stambaugh (1987) and Schwert (1989).

In CW (2005), we have only presented the "Bin Test" results for the 4-bin case with the "full sample" as well as the "equal-sized sample". The 4-bin case divides temperature into 4 ranges. The test results show that there exists a strong negative correlation between temperature and return. That is, for all stock markets, the lower the temperature, the higher the returns, this relationship is generally monotonic.

Recently, Keller, Fredrickson, Ybarra, Côté, Johnson, Mikels, Conway, Wager (2005) study the effects of temperature on mood and cognition. They confirm that people tend to have aggression when temperature is either very high or very low. However, when temperature is in the middle range, say during spring, this aggression disappears and people tend to have clear minds. Their results seem to suggest that people's mood is regulated by 3 different temperature ranges. Based on these findings, it is natural to conjecture that a test based on 3-bin division for temperature should exhibit a stronger negative relationship between temperature and returns. To confirm this, we first perform a 3-bin test for the "full sample" and the "equal-sized sample" (as opposite to the 4-bin case in CW 2005), and then we use the expanded sample to conduct 3-bin and 4-bin tests.

The 3-bin test results are presented in Table 2. Panel A of Table 2 is for the "full sample" while Panel B for the "equal-sized sample". The results are stronger than the 4-bin tests in CW (2005), confirming our conjecture made earlier. In particular, most z-scores are bigger than those for the 4-bin case. For example, for Britain, the z-score for the mean return of the full sample has increased from no significance for the 4-bin case to a 5\% significance level for the 3-bin case. As for Taiwan, the improvements are even stronger. The z-score for the percentage positive returns of the full sample has increased from no significance to $1 \%$ significance while the $\mathrm{z}$-score for the mean return of the equal sample has increased from $5 \%$ significance to $1 \%$ significance. 
Now we briefly discuss the general results for the 3-bin case. For the "full sample", the $z$ statistics of mean return comparisons for all markets other than Canada and Taiwan are significant at the $10 \%$ level, with some being significant at the $5 \%$ and $1 \%$ levels. ${ }^{6}$ For Canada and Taiwan, the $\mathrm{z}$ statistics for frequencies of positive returns are both significant at the $5 \%$. In general, the lower the temperature, the more likely that stocks will experience a positive price change. When we combine all the indices, the relationship remains. For both combinations involving the CRSP equal-weighted and value-weighted indices, the z-scores are all significant at the $1 \%$ level. This confirms that there is universal negative correlation between temperature and stock returns.

For Australia, the z-score is significant at the 5\% level and the ranking of mean returns and frequencies of positive returns is strictly monotonic for the 3-bin case. This is a very important observation in that the same season actually covers different calendar months on the Northern and Southern Hemispheres. It is seen in Figure 1 that temperatures progress in opposite directions on the two hemispheres. The observations for Australia convincingly imply that temperature is a common factor to the stock market returns.

Another observation relates to equal-weighted versus value-weighted indices. Panel A of Table 2 confirms that the temperature impact is much stronger on the CRSP equal-weighted index. As stated in CW (2005), prices of small-cap stocks respond to investors' mood change in a much more pronounced fashion. Nonetheless, it is comforting to realize that what we have uncovered is not driven by a few small-cap stocks.

Panel B of Table 2 contains the 3-bin test results for the "equal-sized sample". This test is aimed at making valid comparisons between markets since the equal-sized sample not only covers the same time period, but also has the same number of observations for all markets. With only a few exceptions, the z-scores are lower than those for the full sample due to fewer observations. As in the 4-bin case in CW (2005), the z-score is significant at the 5\% level for three markets (U.S., Canada and Taiwan), and significant at the $10 \%$ level for one market 
(Sweden). The significance level for Canada and Taiwan is actually higher than that of the full sample. The z-score for the CRSP value-weighted index is no longer significant, which reflects the dominance of small-cap stocks in mood impacts. Evidently, even with a shorter sample period and fewer observations, the general monotonic patterns remain in mean returns and frequencies of positive returns for the 3-bin case, confirming similar finding for the 4-bin case in CW (2005). In addition, when all indices are combined the z-scores are all significant at the $1 \%$ level.

To provide further supporting evidence, we perform 3-bin and 4-bin tests on the expanded sample. To save space, we only report the results with the "equal-sized" expanded sample. Table 3 contains the results for the 3-bin and 4-bin cases. Several observations are in order. First, comparing the top portion of Table 3 with Panel B of Table 2 for the "equal-sized sample", we see a drop in significance for the eight locations we previously examined. This is mainly due to the lower testing power associated with a smaller sample (1509 vs. 2252). Nevertheless, with the exception of Japan (3-bin), the z-score for the bin return comparison is negative for all locations, confirming the previously observed negative correlation between temperature and returns. Second, for the additional markets, seven (out of nineteen) have a negative and significant z-score under the 3-bin test and five under the 4-bin test. Most of the zscores are negative, confirming a negative correlation between temperature and returns. Remarkably, the z-score for Auckland is negative and significant for both the 3-bin and 4-bin tests. The 3-bin z-score is also significant for Australia. The results for the two markets residing on the South Hemisphere once again confirm the universal negative association between temperature and returns. Third, the negative correlation is also observed for the combined sample. For return comparisons, the 4-bin z-scores are significant at the $5 \%$ level for both combinations involving either the CRSP-EW index or the CRSP-VW index, while the 3-bin z-score are nearly significant at the $10 \%$ level. For comparisons of percentages of positive returns, the 3-bin and 4bin z-scores are all significant at the $1 \%$ level for both combinations. 
To summarize, the bin test results in Tables 2 and 3 provide strong evidence in support of the conclusion presented in $\mathrm{CW}$ (2005). That is, there exists an overall negative correlation between temperatures and returns.

\section{B. Regression Analysis - Controlling for Known Anomalies}

As we have reasoned in CW (2005), the bin tests can only establish an association between temperature and returns. They cannot measure the precise correlation; nor can they control for some of the known anomalies in stock returns. The second type of test is the "Regression Analysis" which is used to gain further insights into on the relationship between temperatures and returns while controlling for some known anomalies such as the Monday effect and tax-loss selling effect. The first regression is specified as follows:

$$
r_{t}=\alpha_{1}+\alpha_{2} r_{t-1}+\alpha_{3} D_{t}^{M o n}+\alpha_{4} D_{t}^{T a x}+\alpha_{5} \operatorname{Temp}_{t}+\varepsilon_{t}
$$

where $r_{t}$ is the daily return at time $\mathrm{t}$ for a given index; $D_{t}^{M o n}$ is a dummy variable which equals 1 for Mondays and 0 otherwise; $D_{t}^{\text {Mon }}$ is a dummy variable which equals 1 for the first 10 days of the taxation year and 0 otherwise; $\operatorname{Temp}_{t}$ is the daily temperature at time $\mathrm{t}$, and $\varepsilon_{t}$ is the residual term. The tax year starts on July 1 in Australia, April 6 in Britain and Ireland, April 1 in New Zealand, March 1 in South Africa, and January 1 in all other jurisdictions.

In our previous study (CW 2005), we first run individual OLS regressions for the "full sample" as a preliminary check. Subsequently, we also run a seemingly unrelated regression (SUR) by combining the CRSP value-weighted index with all other indices. It is clear that the full sample results can only be preliminary for several reasons. First, the sample periods are different among markets, making valid comparisons difficult; second, the returns and temperatures are correlated among markets, casting doubt on the validity of the OLS regressions; third, it is impossible to perform joint tests of the temperature variable's significance across markets. The SUR can address these concerns. It takes into account the inter-market correlations and, at the 
same time, allows for joint tests on the temperature coefficients. The first test is designed to determine if all the coefficients are jointly different from zero. It helps establish whether the negative correlations (between temperature and stock returns) observed for individual markets are jointly significant after controlling for inter-market correlations. The second test is aimed at determining whether all coefficients are equal. It helps to ascertain if investors in different markets react to the same temperature change to the same degree.

To provide complementary evidence, this paper presents the SUR results for the CRSP equally-weighted index together with all other indices. For comparison purposes, we replicate the individual OLS results for the "full sample" from CW (2005) and present them in Panel A of Table 4. The SUR results are reported in Panel B of Table 4. In addition, we also perform individual OLS regressions for the "equal-sized sample". For brevity, we only report the temperature variable's coefficient estimate, its t-value, and the $R^{2}$ from the individual regressions. For the seemingly unrelated regressions, we report the system-wide $R^{2}$.

Let us briefly summarize the results for Panel A of Table 4. To begin with, returns on Mondays are lower for all markets with the exception of Sweden and Australia. This Monday effect is significant at the $1 \%$ level for U.S., Canada, Britain, and Germany, and it is significant at the 5\% for Japan and Taiwan. In contrast, the tax loss effect is significant for only U.S. and Australia, and it has the right sign for all markets with the exception of Canada and Japan.

As for the temperature variable, with the exception of Canada and Australia, all markets have a negative coefficient that is significant at the $10 \%$ level. Some are significant at the $5 \%$ and $1 \%$ levels. The significant, negative coefficient for most markets is consistent with the bin test results. The temperature coefficient for Canada is negative and the $t$-value is nearly significant at the $10 \%$ level. For Australia, the coefficient is positive but close to zero in significance. The $R^{2}$ is relatively higher for the U.S. and Canada. In terms of pattern and magnitude, the $R^{2}$ across markets is very similar to that in KKL (2003). 
The temperature coefficient from OLS regressions is negative for all markets, and significant at the 5\% level or higher for U.S., Canada, Germany, Sweden and Taiwan. The t-value for Britain is nearly significant at the $10 \%$ level. Unlike in the full sample, Australia now has a negative coefficient, albeit not a significant one.

The SUR results in Panel B of Table 4 for the CRSP equally-weighted index are stronger than the SUR results in CW (2005) for the CRSP value-weighted index, as we expect. However, the t-values are generally lower than those from the individual OLS regressions. There are several cases (e.g., Germany) where the t-value is significant in the OLS regression but not in the SUR. This is to be expected due to the positive inter-market correlations. Only U.S. (CRSP equalweighted index), Sweden and Taiwan have a t-value significant at the $10 \%$ level or higher. However, the chi-square statistic for the first test is significant at the $1 \%$ level. This means that the negative correlation between temperature and stock returns is jointly significant across all markets. The chi-square statistic for the second test is significant at the $5 \%$ level. These results are consistent with the SUR results presented in CW (2005).

This regression analysis establishes a strong negative correlation between temperature and stock returns after controlling for auto-correlation in returns, the Monday effect and the taxloss effect. The second regression used in our previous study (CW 2005) is to further control some known nature-related anomalies associated with the amount of sunshine in Saunders (1993) and HS (2003) and the seasonal affective disorder (SAD) in KKL (2003). The augmented regression takes the following form:

$$
r_{t}=\alpha_{1}+\alpha_{2} r_{t-1}+\alpha_{3} D_{t}^{\text {Mon }}+\alpha_{4} D_{t}^{\text {Tax }}+\alpha_{5} \text { Temp }_{t}+\alpha_{6} \text { Cloud }_{t}+\alpha_{7} S A D_{t}+\varepsilon_{t},
$$

where Cloud $_{t}$ is the cloud cover and $S A D_{t}$ is the number of night hours minus 12 for the period of September 21 to March 20, and zero otherwise. As stated earlier, to correct for inter-market correlations and to ensure comparability, the SUR is used for this augmented regression. 
To provide further evidence, we present the results with the expanded data set. As in HS (2003), the "total sky cover" from the NCDC is used to measure cloud cover which is the hourly average from 6:00am to 4:00pm. The variable "total sky cover" ranges in value from 0 (clear) to 8 (overcast). Canada, Brazil, Germany and Japan are eliminated from the sample since the sky cover observations are not complete for Toronto, Rio de Janeiro, Frankfurt and Tokyo. Since the cloud cover data are available for the period of 1982 to 1997, for the remaining 23 markets, we match the "equal-sized sample" of temperature (with 1509 observations) with the cloud data. The final sample size is reduced to 1013 with a common sample period ranging from 1989 to 1997. Table 5 reports the mean and standard deviation of cloud cover for each market, and the regression results.

First and foremost, the temperature coefficient for the SUR test is negative for 21 of the 23 markets, and the t-values for five coefficients are significant at the $10 \%$ level or higher. The two chi-square statistics are significant at the 5\% and $10 \%$ levels respectively. For individual regressions, the temperature coefficient is positive for only one market (Malaysia). It is evident that, the negative correlation between temperature and returns is prevalent across markets even after controlling for other known anomalies.

The SAD effect also appears strong in the expanded sample, although none of the chisquare statistics is significant. The SAD coefficient is negative for most of the cities. This negative association between returns and the length of the night confirms the general findings of KKL (2003) who examine nine markets.

As for the sunshine effect, the cloud cover coefficient is negative for many cities, consistent with the findings of HS (2003). However, the coefficient is positive and statistically significant for three cities under either the individual or SUR tests. Therefore, after controlling for temperature and SAD effects, the sunshine effect is no longer uniform across all locations.

Up to now, we have presented more evidence in support of the conclusion drawn in our previous study (CW 2005). That is, there is indeed a "temperature anomaly" in stock markets 
around the globe. Specifically, a statistically significant, negative correlation exists between temperature and stock returns, after controlling for the first order auto-correlation in returns, the Monday effect, the tax loss effect, the cloud cover effect, and the length-of-the-night effect. The statistical significance is obtained in both the individual OLS regressions and the seemingly unrelated regressions which control for inter-market correlations.

In the next section, we propose some additional empirical tests to see whether this negative relationship continues to remain under different specifications.

\section{Alternative Tests and Robustness Check}

Given that the expanded data have a much shorter sample period and the quality of the temperature data from NCDC for this sample is inferior to that of the "full sample", we will use the "full sample" to perform alternative tests in this section.

\section{A. Nonparametric Tests}

The two main tests used in CW (2005) are either semi-parametric (bin tests) or completely parametric (regression tests). It is helpful to know whether those types of analyses are robust to distributional assumptions. To this end, we propose two nonparametric tests, with one testing the general correlation between temperature and stock returns, and the other testing whether investors react to the same temperature change to the same extent. The first, Spearman's rank correlation test, is roughly a nonparametric counterpart of the bin test, but is stronger and more precise; the second, Friedman's two-way analysis of variance, is the nonparametric counterpart of the chi-square test in SUR that tests if all the temperature coefficients are equal.

Unlike the usual Pearson's correlation which requires the data series to be normally distributed, the Spearman's correlation is based on the ranks of the two data series in question and

is therefore distribution-free. The precise formula is $\rho_{s}=1-\left[6 \sum_{i=1}^{n} d_{i}^{2}\right] /\left[n\left(n^{2}-1\right)\right]$ where $\rho_{s}$ is the 
Spearman's rank correlation, $n$ is the number of observations, and $d_{\mathrm{i}}$ is the rank difference for the $i$ th observation. When the number of observations is larger than $10, \rho_{s}$ has a t-distribution with $n$ 2 degrees of freedom, and the test statistic is given by $t=\rho_{s}^{2} \sqrt{(n-2) /\left(1-\rho_{s}^{2}\right)}$.

To avoid spurious correlations, we calculate Spearman's correlation based on temperature bins. Table 1 reveals that the maximum temperature range for the full sample is about 50 degrees. We therefore put temperatures into 50 bins and calculate the mean temperature and return for each bin. A rank correlation is then calculated using the mean temperatures and returns. For robustness check, we also use 30, 40, 60, 70 and 100 bins. The rank correlation is calculated for each individual market and all the markets combined. Panel A of Table 6 reports the results.

When the number of bins is 40,50 or 60 , correlations for all the markets (except Australia) are significant at the $10 \%$ level or higher. Although not significant, the correlation for Australia is negative. With a bin size of 50 , the correlation for all markets combined is significant at the $1 \%$ level (two-tailed test) when the CRSP equal-weighted index is used, and significant at the 5\% level when the CRSP value-weighted index is used. Although the size of the correlations decreases as the number of bins increases (which is a common feature of most time series), the significance remains more or less unchanged.

We now turn to the second nonparametric test. The regression analyses indicate that investors in different temperature domiciles react to temperature changes to different extents. We would like to ascertain if this result holds up to nonparametric tests. We design the test in the following way. We first create temperature bins common to all markets; we then test if returns are equal across markets within each temperature bin or range. This joint test essentially allows us to determine if investors react to the absolute levels of temperature, or to the levels relative to the local norm. In other words, it helps to answer the following question: Does a temperature range of, say $5^{\circ} \mathrm{C}$ to $8^{\circ} \mathrm{C}$ induce the same reaction among investors around the globe? Intuition would 
suggest a negative answer since a cool temperature in one place may be perceived as a warm temperature in another, depending on the local year-round average temperature.

The Friedman's two-way analysis of variance is an ideal choice for our test. Let $\mathrm{k}$ be the number of markets and $\mathrm{n}$ be the number temperature bins. The Friedman's test statistic is then calculated as $\frac{12}{k n(k+1)} \sum_{j=1}^{k} S_{j}^{2}-3 n(k+1)$, where $S_{j}$ is the sum of ranks received by the $j$ th market. This statistic has a chi-square distribution with $(k-1)$ degrees of freedom. Since this is a joint test, we again have two versions of the combination, depending on whether we use the CRSP equalweighted index or the CRSP value-weighted index for U.S.. In addition, we must choose a common temperature range applicable to all markets. Table 1 indicates that, for the full sample, the lowest maximum temperature among all the markets is $26.70^{\circ} \mathrm{C}$ (Sweden), and the highest minimum temperature is $8.15^{\circ} \mathrm{C}$ (Australia). We therefore set $8.15^{\circ} \mathrm{C}$ as the lower bound and $26.70^{\circ} \mathrm{C}$ as the upper bound. Temperature bins are created within this range. The chi-square statistics and their significance are reported in Panel B of Table 6.

With up to five temperature bins, the chi-square statistic is significant at the $5 \%$ or $10 \%$ level, indicating that investors around the globe do not react to the same temperature level to the same extent. In other words, a universal temperature-level effect does not exist across markets. This is consistent with the chi-square test on the temperature coefficients from SUR. When the number of temperature bins is greater than five, the chi-square statistics are no longer significant. With a large number of bins, the temperature range within each bin is too narrow (e.g., it is only $[26.7-8.15] / 6=3.09^{\circ} \mathrm{C}$ with six bins) to pick up return differences.

Overall, our nonparametric tests indicate that, regardless of distributional assumptions and inter-market correlations, a negative correlation between temperature and stock returns exists for individual markets and for all markets combined. Our bin tests and regression analyses are therefore quite robust. 


\section{B. Tests Based on Temperature Deviations}

All tests done here or in CW (2005) show a very strong negative relation between returns and temperature. It is of interest to see whether a similar relation exists between returns and temperature deviations, the latter being the difference between daily temperature and the historical average daily temperature. A positive deviation means a warmer-than-normal day and a negative deviation means the opposite. The absolute level of temperature may capture its overall seasonal impacts on returns, while the temperature deviations can capture the impact of daily temperature shocks.

Since deviations reflect whether a particular day is warmer or colder than normal, and since very cold days are in the winter and very hot days are in the summer, we combine positive deviations for the summer and negative deviations for the winter to perform joint analyses. This approach has three advantages: 1) it uses both positive and negative deviations, 2) it covers the whole year, and 3) it emphasizes the impact of temperature deviations most relevant for the season. Again, we use the equal-size sample for comparability. As evident in Figure 1, the plot of historical average daily temperatures is not very smooth, due to the relatively short sample period. (Keep in mind that even for the longest sample (U.S.), there are only 37 observations for each day of the year.) To smooth the historical average daily temperatures, we calculate moving averages of the historical averages using window sizes of 3, 7, 15, and 31 days. We create two versions of the daily moving average, depending on whether the current day is placed in the middle or at the end of the moving window. As shown in Figure 2 (using New York as an example), including more days in the moving window leads to a smoother curve, as one would expect. With various versions of the daily average, we calculate daily temperature deviations and use them to perform bin tests as in Table 2 and regressions as in (3.1). For brevity, we only report the temperature coefficient and its t-value from OLS regressions in Table 7.

The temperature coefficient is negative for all markets and all sizes of moving windows. The only exception is Japan when the moving window is 15 days. The negative coefficient is 
significant at the $10 \%$ level for U.S. (CRSP equal-weighted index), and significant at the $1 \%$ level for Taiwan. The results do not seem to be sensitive to the smoothing of daily average temperatures, and the $R^{2}$ is largely comparable to that in Table 4 for each regression. Overall, the correlation is understandably weaker in terms of statistical significance since we have removed the level effect. Nonetheless, the consistent sign across markets does imply a negative relation between temperature deviations and stock returns.

The above results confirm that the relationship between temperature and stock market returns is a manifestation of the day-to-day impacts of temperature shocks, as opposed to a reflection of purely seasonal effects. Subtracting the historical average from the realized temperatures amounts to removing any seasonal effects; what remains belongs to the realm of daily impacts. This is a significant point in that, just like the impact of sunshine, the temperature can exert psychological impacts on investors on a daily basis. The correlation between market returns and daily, season-adjusted temperature variations is the ultimate confirmation of temperature impact on investors' behavior.

\section{Aggregating Temperature Impacts across Regions}

We recognize that trades of a particular stock need not be always executed on the floor of the exchange. Stock price movements are due to trading actions of both local brokers / investors and market participants elsewhere. For instance, the trading registered on the NYSE is driven by investors in the city of New York and elsewhere. Conceivably, investors in other parts of the United States may be subject to quite a different weather condition. Therefore, as with the sunshine study of Hirshleifer and Shumway (2003), our study so far is subject to the question of investor concentration in the city which houses the stock exchange. Thankfully, unlike cloud cover or the amount of sunshine, temperatures tend to be highly correlated across regions. An indirect way to measure the aggregate temperature impact on market returns is to calculate the correlation between the average temperature across different regions and the national stock 
market index. This is the route we take. We identify seven major cities in the U.S. which represent the key regions of the country: Atlanta, Chicago, Dallas, Los Angeles, New York, Philadelphia, and Seattle. The daily temperature data for all cities other than New York come from NCDC, which cover the period from January 1, 1982 to December 31, 1997. Two aggregate temperature indices are constructed, with the first being a simple, equally-weighted average of the seven temperature series, and the second being a population-weighted average. Bin tests and regression analyses are then performed using the CRSP indices and the aggregate temperature indices. Table 8 reports the results.

It is seen that the general results for New York city alone from Table 2 (Panel A) and Table 4 (Panel A) also apply here, albeit the statistical significance for most estimates is now lower. It should be realized that the reduction in significance is not simply due to the use of a temperature index. A shorter sample period is undoubtedly another contributing factor, as is evident in Table 2. Nonetheless, a statistically significant, negative correlation between temperature and returns is largely preserved. For instance, three of the z-scores for mean return comparisons under three bins are significant at the $1 \%$ level, and one at the $5 \%$. The $t$-value for the temperature coefficient from regression analyses is significant at the $5 \%$ level for the CRSP equal-weighted index, and is far from zero for the CRSP value-weighted index.

The above observations imply that our empirical findings are not subject to the criticism that the city housing the stock exchange may not represent the entire population of investors. While investors are scattered around the country, they are subject to very similar temperature variations because of the high correlations among regional temperatures.

\section{Sub-Sample Results}

To provide some evidence on the intertemporal stability of the relationship between temperature and returns, we repeat the analyses for sub-samples. As in the previous sub-section, we focus on the U.S. market since the time series have the longest sample period. As shown in 
Table 1, the sample starts on 1962. To utilize all observations and to ensure rough equality between sub-samples, we cut the entire sample into three sub-periods corresponding to 1962 1974, 1975 - 1987, and 1988 - 1999, with the last sub-period approximately matching the equalsize sample period. Bin tests and OLS regression analyses are performed for each sub-sample and each index. By and large, the qualitative relationship between temperature and market returns is quite stable. Quantitatively, the estimated coefficients do not necessarily stay constant over time. To demonstrate this point, we report the regression results in Table 9. It is seen that, for both indices, the coefficient for the temperature variable seems to be on the rise. This is just by chance since sub-sample analyses for other markets failed to produce similar results. Also, as evident in the $\mathrm{t}$-values and the $R^{2}$, the Monday effect, the tax effect and the temperature effect are all stronger in the equal-weighted index than in the value-weighted index for all sub-samples, consistent with the observations from previous tables.

\section{Conclusion}

This is a companion paper to our previous study in Cao and Wei (2005) where we have identified a stock market temperature anomaly. This line of work is parallel to studies which relate stock market returns to nature-related variables such as the amount of sunshine in Sanders (1993) and Hirshleifer and Shumway (2003), the length of day light in Kamstra, Kramer and Levi (2003). The common feature shared by these studies is the same chain of reasoning: environmental variables, such as sunshine, length of day light and temperature, affect people's mood which in turn influences people's behavior. Such thinking is motivated and supported by literature on mood and decision-making. For example, Mehra and Sah (2002) show theoretically that the emotional state of investors will influence equity prices when investors' subjective parameters such as risk-aversion change in response to mood fluctuations.

Saunders (1993) and Hirshleifer and Shumway (2003) demonstrate that less cloud cover is associated with higher returns and the returns on most cloudy days are significantly different 
from the returns on the least cloudy days. Their argument is that investors' mood is upbeat or optimistic on sunny days, which uplifts the stock market returns, and that their pessimistic mood on cloudy days depresses the stock returns. Kamstra, Kramer and Levi (2003) find that lower returns are associated with longer nights. Their explanation rests on the impact of Seasonal Affective Disorder (SAD) on human behavior. They conjecture that lower returns are caused by investors who are depressed because of longer nights.

Our study on temperature anomaly relies on a body of psychological literature concerning the impact of temperature on people's mood and behaviors. The evidence shows that low temperature tends to cause aggression and high temperature tends to cause aggression, hysteria, and apathy. We therefore hypothesize that lower temperature leads to higher stock returns due to investors' aggressive risk-taking, and higher temperature can lead to higher or lower stock returns since aggression and apathy have competing effects on risk-taking. A statistically significant negative relationship between temperature and stock returns is found for 8 international markets in Cao and Wei (2005).

In this companion paper, we expand our previous sample to include additional 19 financial markets studied by either Hirshleifer and Shumway (2003) or Kamstra, Kramer and Levi (2003). We provide strong evidence in support of the uncovered negative relationship between temperature and stock returns. This relationship prevails even after controlling for the Monday effect, the tax loss effect, the sunshine effect and the SAD effect. More importantly, our non-parametric tests, as opposite to the parametric or semi-parametric approaches used in previous studies, demonstrate that this negative relationship is robust to distributional assumptions. Based on the sub-sample analysis, we find that this negative relationship is stable over time. Furthermore, we consider temperature deviation and demonstrate that this negative relationship is not just a level effect. 


\section{REFERENCE}

Allen, A. M. and G. J. Fisher, 1978, Ambient Temperature Effects on Paired Associate Learning, Ergonomics, 21(2), 95-101.

Anderson, C. A., 2001, Heat and violence, Current Directions in Psychological Science, 10, 3338.

Baron, R.A. and V.M. Ransberger, 1978, Ambient Temperature and the Occurrence of Collective Violence: The Long, Hot Summer Revisited, Journal of Personality and Social Psychology, 36, 351-360.

Bell, P. A. and R. A. Baron, 1976, Aggression and Heat: The Mediating Role of Negative Affect, Journal of Applied Social Psychology, 6, 18-30.

Bell, P.A., 1981, Physiological Comfort, Performance and Social Effects of Heat Stress, Journal of Social Issues, 37, 71-94.

Cao, M. and J. Wei, 2005, Stock Market Returns: a Note on Temperature Anomaly, Journal of Banking and Finance, Vol. 29, 1559-1573.

Cunningham, M. R., 1979, Weather, Mood and Helping Behavior: Quasi-Experiment with the Sunshine Samaritan, Journal of Personality and Social Psychology, 37, 1947-1956.

Dichev, I. D. and T. D. Janes, 2003, Lunar Cycle Effects in Stock Returns, Journal of Private Equity, Vol. 6, No. 4, 8-29.

Etzioni, A., 1988, Normative-Affective Factors: Towards a New Decision-Making Model, Journal of Economic Psychology, 9 (2), 125-150.

French, K. R., Schwert, G. W. and R. F. Stambaugh, 1987, Expected Stock Returns and Volatility, Journal of Financial Economics, 19, 3-29.

Hanock, Y., 2002, "Neither an Angel nor am Ant”: Emotion as an Aid to Bounded 
Rationality, Journal of Economic Psychology, 23 (1), 1-25.

Hirshleifer, D. and T. Shumway, 2003, Good Day Sunshine: Stock Returns and the Weather, Journal of Finance, 58 (3).

Howarth E. and M. S. Hoffman, 1984, A Multidimensional Approach to the Relationship between Mood and Weather, British Journal of Psychology, 75, 15-23.

Kamstra, M. J., L. A. Kramer, and M. D. Levi, 2003, Winter Blues: A SAD Stock Market Cycle, American Economic Review, 93 (1), 324-333.

Keller, M. C., Fredrickson, B. L., Ybarra, O., Côté, S., Johnson, K., Mikels, J., Conway, A., \& Wager, T., 2005, A warm heart and a clear head: The contingent effects of weather on mood and cognition", Psychological Science, forthcoming.

Loewenstein, George F., Elke U. Weber, Christopher K. Hsee, and Ned Welch, 2001, Risk as Feelings, Psychological Bulletin, 127 (2), 267-286.

Mehra, R. and R. Sah, 2002, Mood Fluctuations, Projection Bias and Volatility of Equity Prices, Journal of Economic Dynamics and Control, 26, 869-887.

Palamerek, D. L. and Rule, B. G., 1980, The Effects of Ambient Temperature and Insult on the Motivation to Retaliate or Escape, Motivation and Emotion, 3, 83-92.

Parsons, A. G., 2001, The Association Between Daily Weather and Daily Shopping Patterns, Australasian Marketing Journal, 9 (2), 78-84.

Persinger, M. A. (1980). The Weather Matrix and Human Behavior. New York: Praeger Press.

Pilcher, J. J., E. Nadler and C. Busch, 2002, Effects of Hot and Cold Temperature Exposure on Performance: A Meta-Analytic Review, Ergonomics, 45 (10), 682698.

Rind, B., 1996, Effects of Beliefs about Weather Conditions on Tipping, Journal of Applied Social Psychology, 26, 137-147.

Romer, P. M., 2000, Thinking and Feeling, American Economic Review, 90 (2), 439-443. 
Rotton, J., and E. G. Cohn, 2000, Violence is a Curvilinear Function of Temperature in Dallas: a Replication. Journal of Personality \& Social Psychology, 78, 1074-1081.

Sanders, J. L. and M. S. Brizzolara, 1982, Relationship between Mood and Weather, Journal of General Psychology, 107, 157-158.

Saunders, E. M. J., 1993, Stock Prices and Wall Street Weather, American Economic Review, 83, 1337-1345.

Schneider, F. W., Lesko, W. A. and W. A. Garrett, 1980, Helping Behavior in Hot, Comfortable and Cold Temperature: A Field Study, Environment and Behavior, 2, 231-241.

Schwarz, N., 1990, Feelings as Information: Informational and Motivational Functions of Affective States, in E. Tory Higgins and Richard M. Sorrentino (eds.), Handbook of Motivation and Cognition (Vol 2, 527-561). Guilford Press, New York.

Schwert, G. W., 1989, Why Does Stock Market Volatility Change Over Time?, Journal of Finance, 44, 1115-1153.

Watson, D., 2000, Situational and Environmental Influence on Mood, Chapter 3 of Mood and Temperament, Guilford Press, New York.

Wyndham, H. C., 1969, Adaptation to Heat and Cold, Environmental Research, 2, $442-$ 469.

Yuan, K., L. Zheng and Q. Zhu, 2001, Are Investors Moonstruck? Lunar Phases and Stock Returns, Journal of Empirical Finance, forthcoming. 


\section{ENDNOTES}

${ }^{1}$ Other authors, such Dichev and Janes (2003), Yuan, Zheng and Zhu (2001), line stock market returns to lunar cycle. While Dichev and Janes (2001) focused on the U.S. market only, Yuan, Zheng and Zhu (2001) examined 48 international markets in depth. After removing the usual anomalies such as the January effect and the day-of-the-week effect, they showed that stock returns are much lower on days around a full moon than on days around a new moon.

${ }^{2}$ For comprehensive studies regarding temperature impacts on human behaviors, please refer to Allen and Fisher (1978), Anderson (2000), Baron and Ransberger (1978), Bell (1981), Bell and Baron (1976), Cunningham (1979), Howarth and Hoffman (1984), Keller, Fredrickson, Ybarra, Côté, Johnson, Mikels, Conway, Wager (2005), Palamerek and Rule (1980), Parsons (2001), Persinger (1980), Pilcher, Nadler and Busch (2002), Rind (1996), Rotton and Cohn (2002), Sanders and Brizzolara (1982), Schneider, Lesko and Garrett (1980), Watson (2000), Wyndham (1969).

${ }^{3}$ EarthSat's home page: http://www.earthsat.com. This is the company which provides quality temperature data for the settlement of weather derivative contracts traded at the Chicago Mercantile Exchange.

${ }^{4}$ Returns and standard deviations are always expressed in percentage forms throughout the paper.

5 "Historical average daily temperature" refers to the average of daily temperature for each calendar day in the sample period. There are 366 such averages, including February 29 in leap years.

${ }^{6}$ Following our study (CW 2005), we only report two-tail tests throughout the paper. We use two-tail tests for conservative reasons, although we have a strong prior that an overall negative correlation exists between temperature and stock returns. Please note that, for one-tail tests at the $10 \%$ significance level, the critical z-score or t-value for a large enough sample is 1.282. 
Figure 1: Historical Daily Average Temperature

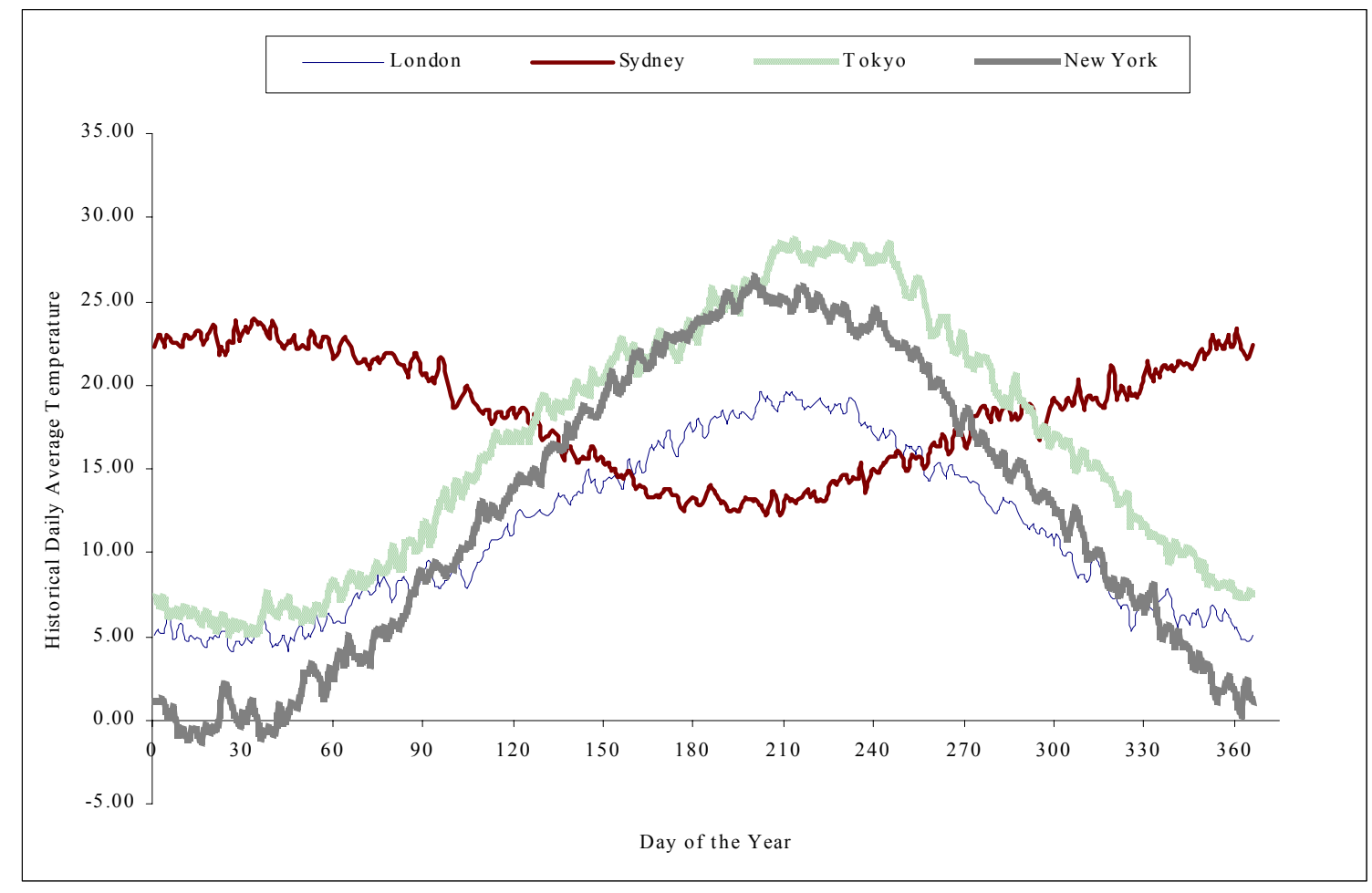


Figure 2: Moving Average of Historical Daily Average Temperature for New York

Panel A: 3-day Moving Average

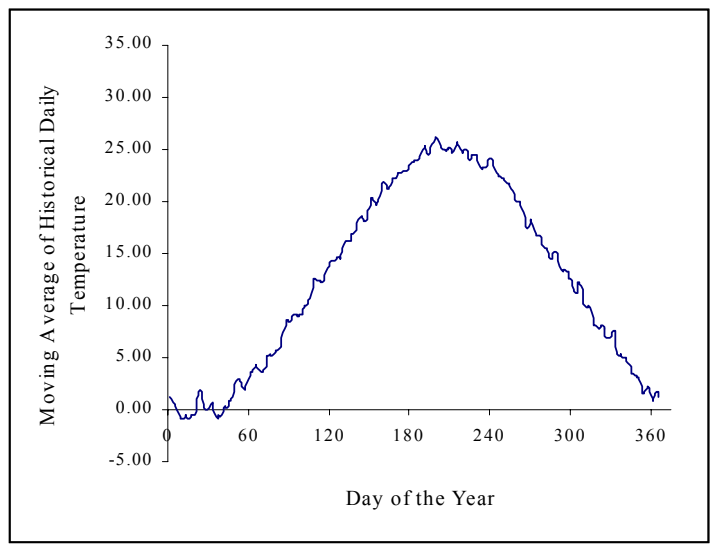

Panel C: 15-day Moving Average

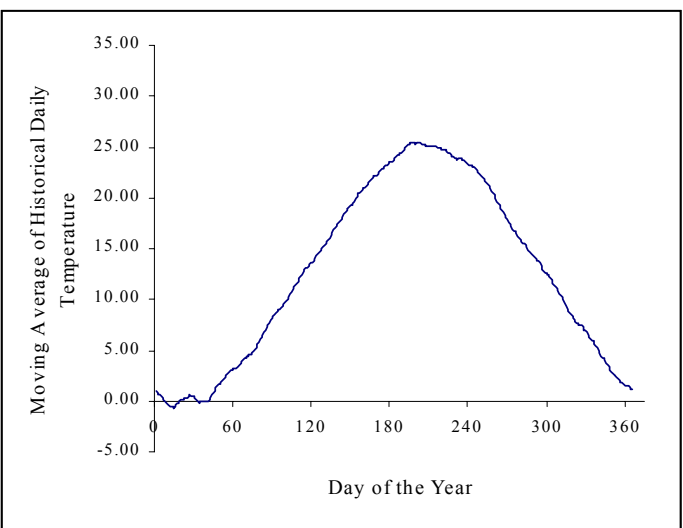

Panel B: 7-day Moving Average

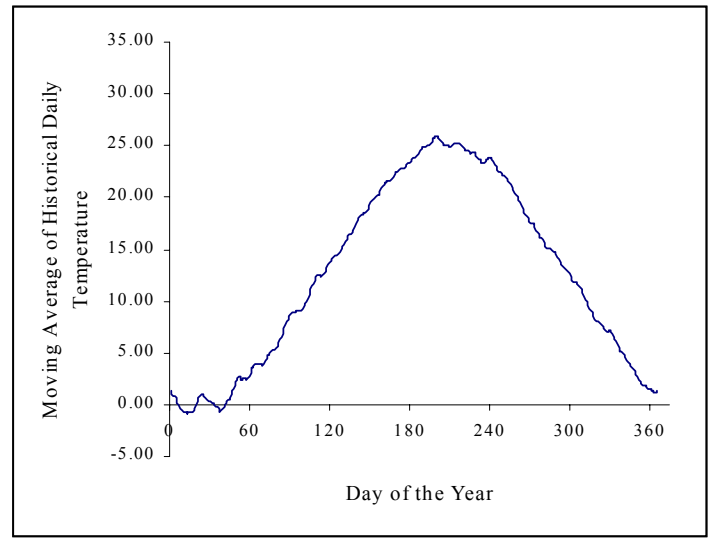

Panel D: 31-day Moving Average

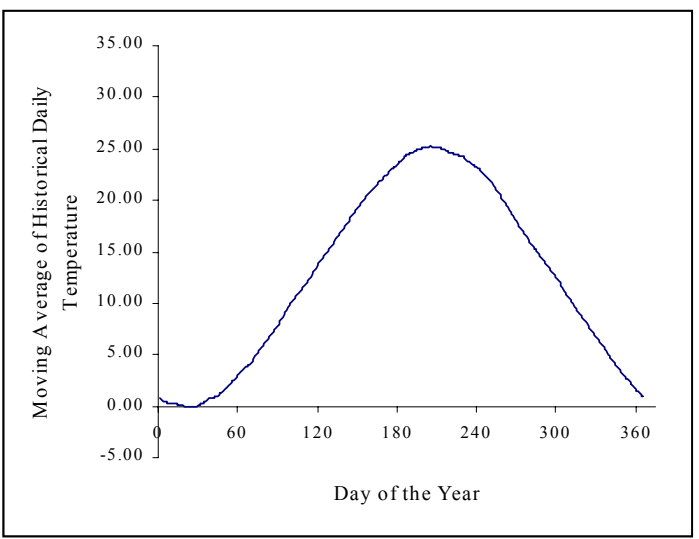

Notes:

1. The plots are for the moving average of the historical daily average temperatures presented in Figure 1. The moving window symmetrically straddles the current day. For example, in the case of a 3-day moving window, we use the temperatures for the previous day, the current day and the next day to calculate the moving average.

2. To obtain the moving average for days at the beginning and end of the year, we simply stack the historical daily average temperatures. To continue the above example, the moving average for January 1 is calculated using the historical daily average temperatures for December 31, January 1 and January 2. 
Table 1: Summary Statistics

Panel A: Daily Returns

\begin{tabular}{|c|c|c|c|c|c|c|c|c|c|}
\hline \multirow[b]{2}{*}{ City, Country/State } & \multirow[b]{2}{*}{ Latitude } & \multirow{2}{*}{$\begin{array}{c}\text { Sample } \\
\text { Period }\end{array}$} & \multicolumn{7}{|c|}{ Daily Return (\%) } \\
\hline & & & \# of obs. & Mean & Std. Dev. & Min & Max & Skew & Kurt \\
\hline \multicolumn{10}{|c|}{ Financial Markets and Locations Examined in Cao and Wei (2005) } \\
\hline New York, U.S.A (CRSP-EW) & $41^{0} 46^{\prime} \mathrm{N}$ & $62-99$ & 9442 & 0.075 & 0.068 & -10.484 & 6.944 & -1.110 & 16.980 \\
\hline New York, U.S.A (CRSP-VW) & $41^{0} 46^{\prime} \mathrm{N}$ & $62-99$ & 9442 & 0.051 & 0.821 & -17.173 & 8.669 & -1.120 & 26.220 \\
\hline Toronto, Canada & $43^{0} 41^{\prime} \mathrm{N}$ & $77-01$ & 6099 & 0.036 & 0.850 & -12.010 & 8.650 & -1.130 & 16.470 \\
\hline London, Britain & $51^{0} 29^{\prime} \mathrm{N}$ & $84-01$ & 4285 & 0.038 & 0.985 & -13.029 & 7.597 & -0.990 & 13.900 \\
\hline Frankfurt, Germany & $50^{0} 03^{\prime} \mathrm{N}$ & $70-01$ & 7901 & 0.028 & 1.124 & -13.706 & 8.862 & -0.480 & 8.050 \\
\hline Stockholm, Sweden & $50^{0} 21^{\prime} \mathrm{N}$ & $89-01$ & 3129 & 0.054 & 1.426 & -7.491 & 13.142 & 0.320 & 6.200 \\
\hline Sydney, Austrlia & $33^{0} 57 ' \mathrm{~S}$ & $84-00$ & 4145 & 0.036 & 1.012 & -28.713 & 5.739 & -6.160 & 162.380 \\
\hline Tokyo, Japan & $35^{0} 41^{\prime} \mathrm{N}$ & $84-01$ & 4314 & 0.005 & 1.364 & -16.135 & 12.430 & -0.120 & 9.170 \\
\hline Taipei, Taiwan & $25^{0} 02^{\prime} \mathrm{N}$ & $77-01$ & 6777 & 0.037 & 1.675 & -9.710 & 7.581 & -0.270 & 2.810 \\
\hline \multicolumn{10}{|c|}{ Additional Financial Markets and Locations Examined in Hirshleifer and Shumway (2003) and Kamstra, Kramer, Levi (2003) } \\
\hline Amsterdam, Netherlands & $52^{0} 18^{\prime} \mathrm{N}$ & $82-97$ & 4173 & 0.056 & 0.887 & -11.032 & 7.936 & -0.645 & 13.120 \\
\hline Athens, Greece & $37^{0} 54^{\prime} \mathrm{N}$ & $88-97$ & 2607 & 0.082 & 1.756 & -14.632 & 15.311 & 0.070 & 10.334 \\
\hline Auckland, New Zealand & $37^{0} 01^{\prime} \mathrm{S}$ & $88-97$ & 2608 & 0.024 & 1.181 & -12.788 & 9.153 & -0.248 & 14.118 \\
\hline Buenos Aires, Argentina & $34^{0} 49^{\prime} \mathrm{S}$ & $88-97$ & 2605 & 0.418 & 3.775 & -19.612 & 26.182 & 1.363 & 8.133 \\
\hline Copenhagen, Demark & $55^{0} 38^{\prime} \mathrm{N}$ & $82-97$ & 4173 & 0.054 & 0.869 & -8.929 & 6.009 & -0.577 & 8.045 \\
\hline Dublin, Ireland & $53^{0} 26^{\prime} \mathrm{N}$ & $82-97$ & 4173 & 0.063 & 1.043 & -15.485 & 8.700 & -1.277 & 23.335 \\
\hline Helsinki, Finland & $60^{0} 19^{\prime} \mathrm{N}$ & $87-97$ & 2869 & 0.041 & 1.104 & -12.540 & 8.742 & -0.532 & 11.759 \\
\hline Istanbul, Turkey & $40^{0} 58^{\prime} \mathrm{N}$ & $88-97$ & 2607 & 0.241 & 2.606 & -12.220 & 13.165 & -0.097 & 2.324 \\
\hline Johannesburg, South Africa & $26^{0} 08^{\prime} \mathrm{S}$ & $82-97$ & 4173 & 0.067 & 1.236 & -14.528 & 7.915 & -1.392 & 15.836 \\
\hline Kuala Lumpur, Malaysia & $03^{0} 07^{\prime} \mathrm{N}$ & $82-97$ & 4174 & 0.011 & 1.403 & -17.067 & 11.666 & -1.080 & 19.328 \\
\hline Madrid, Spain & $40^{0} 27^{\prime} \mathrm{N}$ & $82-97$ & 4174 & 0.058 & 1.015 & -9.734 & 6.939 & -0.387 & 7.885 \\
\hline Manila, Philippines & $14^{0} 31^{\prime} \mathrm{N}$ & $86-97$ & 3130 & 0.085 & 1.878 & -15.786 & 15.657 & 0.052 & 10.369 \\
\hline Milan, Italy & $45^{0} 26^{\prime} \mathrm{N}$ & $82-97$ & 4173 & 0.043 & 1.221 & -8.435 & 8.402 & -0.185 & 4.363 \\
\hline Oslo, Norway & $60^{0} 12^{\prime} \mathrm{N}$ & $82-97$ & 4173 & 0.059 & 1.366 & -21.087 & 10.321 & -1.029 & 20.879 \\
\hline Paris, France & $49^{0} 01^{\prime} \mathrm{N}$ & $82-97$ & 4173 & 0.053 & 1.005 & -9.895 & 7.967 & -0.642 & 8.878 \\
\hline Rio de Janeiro, Brazil & $22^{0} 54^{\prime} \mathrm{S}$ & $86-97$ & 3107 & 0.662 & 3.709 & -17.714 & 22.813 & 0.188 & 2.299 \\
\hline Santiago, Chile & $33^{0} 23^{\prime} \mathrm{S}$ & $87-97$ & 2869 & 0.101 & 0.987 & -12.304 & 6.471 & -0.432 & 12.771 \\
\hline Vienna, Austria & $48^{0} 07^{\prime} \mathrm{N}$ & $83-97$ & 3911 & 0.049 & 0.920 & -9.250 & 7.703 & -0.183 & 14.877 \\
\hline Zurich, Switzerland & $47^{0} 23^{\prime} \mathrm{N}$ & $82-97$ & 4173 & 0.056 & 0.826 & -12.310 & 6.620 & -2.193 & 31.223 \\
\hline
\end{tabular}

Note:

Daily returns are in percentage forms. For example, the mean return for Amsterdam is $.056 \%$. 
Table 1: Summary Statistics

... Continued

Panel B: Daily Temperature (Celsius)

\begin{tabular}{|c|c|c|c|c|c|c|c|c|c|}
\hline \multirow[b]{2}{*}{ City, Country/State } & \multirow[b]{2}{*}{ Latitude } & \multirow{2}{*}{$\begin{array}{c}\text { Sample } \\
\text { Period }\end{array}$} & \multicolumn{7}{|c|}{ Daily Temperature (Celsius) } \\
\hline & & & \# of obs. & Mean & Std. Dev. & Min & $\operatorname{Max}$ & Skew & Kurt \\
\hline \multicolumn{10}{|c|}{ Financial Markets and Locations Examined in Cao and Wei (2005) } \\
\hline New York, U.S.A & $41^{0} 46^{\prime} \mathrm{N}$ & $62-99$ & 13696 & 12.71 & 9.62 & -16.39 & 34.44 & -0.19 & -0.89 \\
\hline Toronto, Canada & $43^{0} 41^{\prime} \mathrm{N}$ & $77-01$ & 8835 & 7.61 & 10.59 & -24.70 & 30.35 & -0.23 & -0.82 \\
\hline London, Britain & $51^{0} 29{ }^{\prime} \mathrm{N}$ & $84-01$ & 6189 & 11.23 & 5.67 & -7.55 & 27.40 & -0.02 & -0.60 \\
\hline Frankfurt, Germany & $50^{0} 03^{\prime} \mathrm{N}$ & $70-01$ & 11508 & 10.08 & 7.41 & -14.20 & 29.30 & -0.11 & -0.65 \\
\hline Stockholm, Sweden & $50^{0} 21^{\prime} \mathrm{N}$ & $89-01$ & 4558 & 6.97 & 7.78 & -20.95 & 26.70 & -0.08 & -0.65 \\
\hline Sydney, Austrlia & $33^{0} 57^{\prime} \mathrm{S}$ & $84-00$ & 5992 & 18.30 & 4.10 & 8.15 & 32.00 & 0.11 & -0.65 \\
\hline Tokyo, Japan & $35^{0} 41^{\prime} \mathrm{N}$ & $84-01$ & 6396 & 16.34 & 7.91 & -0.90 & 33.40 & 0.06 & -1.15 \\
\hline Taipei, Taiwan & $25^{0} 02^{\prime} \mathrm{N}$ & $77-01$ & 8373 & 22.81 & 5.50 & -1.55 & 34.00 & -0.32 & -0.85 \\
\hline \multicolumn{10}{|c|}{ Additional Financial Markets and Locations Examined in Hirshleifer, Shumway (2003) and Kamstra, Kramer, Levi (2003) } \\
\hline Amsterdam, Netherlands & $52^{0} 18^{\prime} \mathrm{N}$ & $82-97$ & 5778 & 9.74 & 6.08 & -11.80 & 25.50 & -0.21 & -0.21 \\
\hline Athens, Greece & $37^{0} 54^{\prime} \mathrm{N}$ & $88-97$ & 3604 & 18.01 & 7.11 & 0.60 & 35.00 & 0.05 & -1.14 \\
\hline Auckland, New Zealand & $37^{0} 01$ 's & $88-97$ & 3648 & 15.12 & 4.11 & 2.00 & 33.00 & -0.21 & 0.03 \\
\hline Buenos Aires, Argentina & $34^{0} 49^{\prime} \mathrm{S}$ & $88-97$ & 3536 & 17.00 & 5.99 & 1.70 & 32.65 & -0.15 & -0.78 \\
\hline Copenhagen, Demark & $55^{0} 38^{\prime} \mathrm{N}$ & $82-97$ & 5844 & 8.20 & 6.80 & -17.00 & 25.90 & -0.09 & -0.62 \\
\hline Dublin, Ireland & $53^{0} 26^{\prime} \mathrm{N}$ & $82-97$ & 5796 & 9.79 & 4.39 & -3.60 & 22.00 & 0.02 & -0.68 \\
\hline Helsinki, Finland & $60^{\circ} 19^{\prime} \mathrm{N}$ & $87-97$ & 3955 & 4.94 & 8.80 & -34.25 & 24.85 & -0.31 & -0.05 \\
\hline Istanbul, Turkey & $40^{0} 58^{\prime} \mathrm{N}$ & $88-97$ & 3264 & 14.53 & 7.49 & -4.00 & 29.30 & -0.05 & -1.18 \\
\hline Johannesburg, South Africa & $26^{0} 08^{\prime} \mathrm{S}$ & $82-97$ & 5467 & 16.19 & 4.33 & 0.45 & 27.00 & -0.45 & -0.38 \\
\hline Kuala Lumpur, Malaysia & $03^{0} 07^{\prime} \mathrm{N}$ & $82-97$ & 5830 & 27.79 & 1.01 & 21.50 & 33.60 & -0.38 & 1.22 \\
\hline Madrid, Spain & $40^{\circ} 27^{\prime} \mathrm{N}$ & $82-97$ & 5816 & 14.37 & 7.38 & -3.50 & 31.60 & 0.18 & -0.99 \\
\hline Manila, Philippines & $14^{0} 31^{\prime} \mathrm{N}$ & $86-97$ & 4375 & 27.69 & 1.76 & 14.50 & 32.50 & -1.19 & 6.49 \\
\hline Milan, Italy & $45^{0} 26^{\prime} \mathrm{N}$ & $82-97$ & 5806 & 13.21 & 8.19 & -10.05 & 29.60 & -0.07 & -1.1 \\
\hline Oslo, Norway & $60^{0} 12^{\prime} \mathrm{N}$ & $82-97$ & 5460 & 4.24 & 8.85 & -27.95 & 23.50 & -0.34 & -0.31 \\
\hline Paris, France & $49^{0} 01^{\prime} \mathrm{N}$ & $82-97$ & 5387 & 11.27 & 6.58 & -13.50 & 30.70 & -0.14 & -0.41 \\
\hline Rio de Janeiro, Brazil & $22^{0} 54$ 'S & $86-97$ & 4242 & 21.89 & 2.84 & 11.00 & 33.00 & -0.07 & -0.44 \\
\hline Santiago, Chile & $33^{0} 23^{\prime} \mathrm{S}$ & $87-97$ & 3983 & 7.32 & 4.38 & -6.00 & 22.00 & -0.46 & -0.51 \\
\hline Vienna, Austria & $48^{0} 07^{\prime} \mathrm{N}$ & $83-97$ & 5478 & 5.67 & 7.57 & -22.00 & 23.00 & -0.35 & -0.42 \\
\hline Zurich, Switzerland & $47^{0} 23^{\prime} \mathrm{N}$ & $82-97$ & 5692 & 6.33 & 6.65 & -20.20 & 22.00 & -0.22 & -0.51 \\
\hline
\end{tabular}

Note:

For daily temperature, due to missing observations, the number of observations across cities can be quite different even within the same sample period. 
Table 2: Bin Tests

\begin{tabular}{|c|c|c|c|c|c|c|c|c|c|}
\hline & & \multicolumn{4}{|c|}{ Panel A: Full-Sized Sample } & \multicolumn{4}{|c|}{ Panel B: Equal-Sized Sample } \\
\hline & & \multicolumn{4}{|c|}{$\#$ of bins $=3$} & \multicolumn{4}{|c|}{$\#$ of bins $=3$} \\
\hline & & bin 1 & bin 2 & bin 3 & z-score $_{3,1}$ & bin 1 & bin 2 & bin 3 & z-score $_{3,1}$ \\
\hline \multirow[t]{3}{*}{ U.S. CRSP-EW } & Return Mean & 0.0020 & 0.0008 & 0.0003 & $-7.4261 * * *$ & 0.0018 & 0.0012 & 0.0006 & $-2.9372 * * *$ \\
\hline & Std. Dev. of Return & 0.0064 & 0.0072 & 0.0063 & & 0.0048 & 0.0055 & 0.0060 & \\
\hline & $\%$ of Positive Returns & 0.6780 & 0.6079 & 0.5868 & $-5.5041 * * *$ & 0.7312 & 0.6444 & 0.6406 & $-2.4926 * *$ \\
\hline \multirow[t]{3}{*}{ U.S. CRSP-VW } & Return Mean & 0.0009 & 0.0006 & 0.0003 & $-2.3042 * *$ & 0.0010 & 0.0007 & 0.0003 & -1.2758 \\
\hline & Std. Dev. of Return & 0.0071 & 0.0087 & 0.0078 & & 0.0067 & 0.0079 & 0.0080 & \\
\hline & $\%$ of Positive Returns & 0.5855 & 0.5432 & 0.5428 & $-2.4684 * *$ & 0.6022 & 0.5459 & 0.5599 & -1.0655 \\
\hline \multirow[t]{3}{*}{ Canada } & Return Mean & 0.0007 & 0.0003 & 0.0002 & -1.4287 & 0.0009 & 0.0004 & -0.0002 & -2.4993 ** \\
\hline & Std. Dev. of Return & 0.0082 & 0.0092 & 0.0077 & & 0.0064 & 0.0072 & 0.0070 & \\
\hline & $\%$ of Positive Returns & 0.5737 & 0.5414 & 0.5304 & $-2.1973 * *$ & 0.5817 & 0.5499 & 0.5257 & -1.6166 \\
\hline \multirow[t]{3}{*}{ Britain } & Return Mean & 0.0016 & 0.0002 & 0.0004 & $-2.3702 * *$ & 0.0012 & 0.0001 & 0.0003 & -1.3803 \\
\hline & Std. Dev. of Return & 0.0091 & 0.0103 & 0.0089 & & 0.0088 & 0.0089 & 0.0087 & \\
\hline & $\%$ of Positive Returns & 0.5702 & 0.5187 & 0.5375 & -1.1737 & 0.5201 & 0.5109 & 0.5399 & 0.5744 \\
\hline \multirow[t]{3}{*}{ Germany } & Return Mean & 0.0011 & 0.0002 & 0.0002 & $-2.0186^{* *}$ & 0.0006 & 0.0003 & 0.0001 & -0.6123 \\
\hline & Std. Dev. of Return & 0.0108 & 0.0116 & 0.0106 & & 0.0140 & 0.0125 & 0.0116 & \\
\hline & $\%$ of Positive Returns & 0.5385 & 0.5135 & 0.5167 & -1.0454 & 0.5427 & 0.5266 & 0.5180 & -0.7586 \\
\hline \multirow[t]{3}{*}{ Sweden } & Return Mean & 0.0022 & 0.0008 & -0.0001 & $-2.1230^{* *}$ & 0.0023 & 0.0009 & 0.0000 & $-1.7096 *$ \\
\hline & Std. Dev. of Return & 0.0129 & 0.0153 & 0.0126 & & 0.0128 & 0.0140 & 0.0117 & \\
\hline & $\%$ of Positive Returns & 0.5613 & 0.5256 & 0.5206 & -0.9566 & 0.5714 & 0.5240 & 0.5331 & -0.7234 \\
\hline \multirow[t]{3}{*}{ Australia } & Return Mean & 0.0007 & 0.0003 & -0.0006 & $-2.2800 * *$ & 0.0006 & 0.0001 & -0.0002 & -1.1299 \\
\hline & Std. Dev. of Return & 0.0080 & 0.0114 & 0.0088 & & 0.0078 & 0.0088 & 0.0094 & \\
\hline & $\%$ of Positive Returns & 0.5306 & 0.5284 & 0.5018 & -0.8844 & 0.5208 & 0.5222 & 0.5179 & -0.0724 \\
\hline \multirow[t]{3}{*}{ Japan } & Return Mean & 0.0006 & -0.0002 & -0.0002 & $-1.7398 *$ & -0.0003 & 0.0001 & -0.0007 & -0.4569 \\
\hline & Std. Dev. of Return & 0.0128 & 0.0147 & 0.0130 & & 0.0151 & 0.0145 & 0.0148 & \\
\hline & $\%$ of Positive Returns & 0.5380 & 0.4983 & 0.5066 & -1.5900 & 0.5048 & 0.4956 & 0.4845 & -0.7422 \\
\hline \multirow[t]{3}{*}{ Taiwan } & Return Mean & 0.0024 & 0.0008 & 0.0000 & -1.3377 & 0.0033 & 0.0003 & -0.0012 & $-3.0655^{* * *}$ \\
\hline & Std. Dev. of Return & 0.0128 & 0.0167 & 0.0168 & & 0.0215 & 0.0189 & 0.0202 & \\
\hline & $\%$ of Positive Returns & 0.6923 & 0.5309 & 0.5130 & $-2.7795 * * *$ & 0.5388 & 0.5048 & 0.4806 & $-1.6800 *$ \\
\hline \multirow{2}{*}{$\begin{array}{l}\text { U.S. CRSP-EW } \\
\text { with }\end{array}$} & Return Mean & 0.0014 & 0.0005 & 0.0003 & $-5.3787 * * *$ & 0.0015 & 0.0005 & 0.0000 & $-4.0728 * * *$ \\
\hline & Std. Dev. of Return & 0.0088 & 0.0109 & 0.0122 & & 0.0086 & 0.0119 & 0.0149 & \\
\hline Other Indices & $\%$ of Positive Returns & 0.6028 & 0.5419 & 0.5363 & $-5.7902 * * *$ & 0.5968 & 0.5366 & 0.5204 & $-3.8067 * * *$ \\
\hline \multirow{2}{*}{$\begin{array}{l}\text { U.S. CRSP-VW } \\
\text { with }\end{array}$} & Return Mean & 0.0011 & 0.0004 & 0.0002 & $-3.9778 * * *$ & 0.0013 & 0.0005 & -0.0001 & $-3.7565 * * *$ \\
\hline & Std. Dev. of Return & 0.0090 & 0.0111 & 0.0124 & & 0.0088 & 0.0121 & 0.0150 & \\
\hline Other Indices & $\%$ of Positive Returns & 0.5777 & 0.5277 & 0.5272 & $-4.3666 * * *$ & 0.5794 & 0.5256 & 0.5126 & $-3.3064 * * *$ \\
\hline
\end{tabular}

Notes:

1. This table reports bin-test results for the full sample and the equal-size sample. The length of the full sample varies across markets; that of the equal-size sample covers the period of 1989-1999 with 2252 observations. We report the mean return and the percentage of positive returns for each of the three bins and the z-scores.

2. $z_{-}$score ${ }_{k, 1}^{\text {mean }}=\left(\mu_{k}-\mu_{1}\right) / \sqrt{\frac{\sigma_{k}^{2}}{n_{k}}+\frac{\sigma_{1}^{2}}{n_{1}}}$ and $z_{-}$score ${ }_{k, 1}^{\text {frequence }}=\left(p_{k}-p_{1}\right) / \sqrt{\frac{p_{k}\left(1-p_{k}\right)}{n_{k}}+\frac{p_{1}\left(1-p_{1}\right)}{n_{1}}}$, where $\mu_{i}$ and $\sigma_{i}$ are the return mean and standard deviation for bin $i$; $p_{i}$ is the percentage of positive returns in bin $i ; n_{i}$ is the number of observations in bin $i$ for each statistic.

3. The asterisks ${ }^{*},{ }^{* *}$, and ${ }^{* * *}$ indicate statistical significance at the $10 \%, 5 \%$ and $1 \%$ levels, respectively (two-sided test). 
Table 3: Bin-Test for Expanded Sample with Equal Size

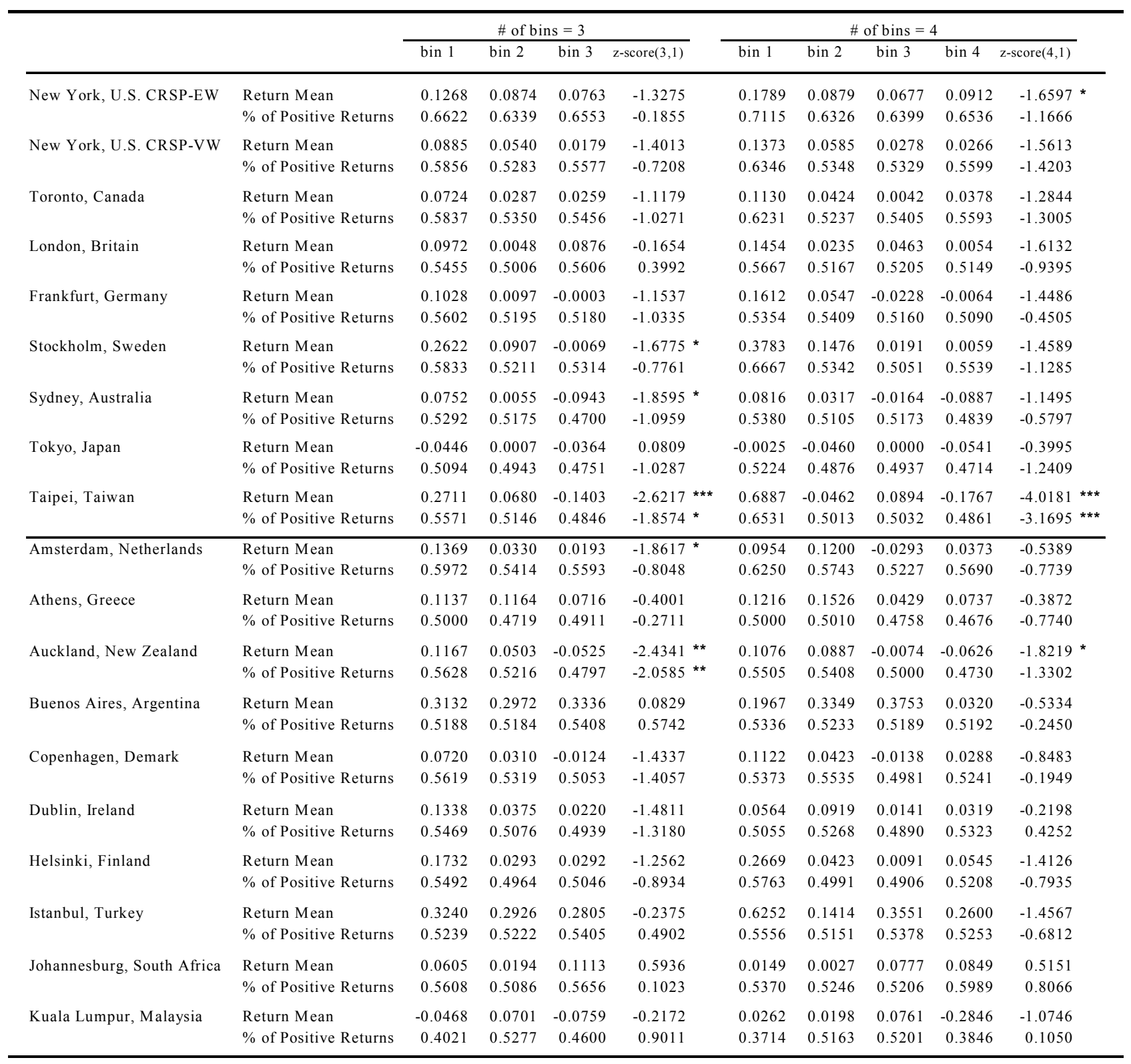


Table 3: Bin-Test for Expanded Sample with Equal-Size

... Continued

\begin{tabular}{|c|c|c|c|c|c|c|c|c|c|c|c|c|}
\hline & & \multicolumn{5}{|c|}{$\#$ of bins $=3$} & \multicolumn{5}{|c|}{$\#$ of bins $=4$} & \\
\hline & & bin 1 & bin 2 & bin 3 & z-score $(3,1)$ & & bin 1 & bin 2 & bin 3 & bin 4 & z-score $(4,1)$ & \\
\hline \multirow[t]{2}{*}{ Madrid, Spain } & Return Mean & 0.0766 & 0.0414 & -0.0584 & -1.9528 & 3 * & 0.0722 & 0.0865 & -0.0497 & -0.0384 & -1.3048 & \\
\hline & $\%$ of Positive Returns & 0.5303 & 0.4937 & 0.4720 & -1.6408 & & 0.5160 & 0.5090 & 0.4746 & 0.4915 & -0.5238 & \\
\hline \multirow[t]{2}{*}{ Manila, Philippines } & Return Mean & 0.0931 & -0.0638 & 0.0270 & -0.1707 & & 0.1668 & 0.4531 & -0.0157 & 0.0328 & -0.3037 & \\
\hline & $\%$ of Positive Returns & 0.5000 & 0.5000 & 0.4970 & -0.0170 & & 0.5714 & 0.6364 & 0.4924 & 0.5026 & -0.3654 & \\
\hline \multirow[t]{2}{*}{ Milan, Italy } & Return Mean & 0.1552 & 0.0411 & -0.0511 & -2.3793 & $3 * *$ & 0.2489 & 0.0132 & 0.0265 & -0.0365 & -2.5343 & $* *$ \\
\hline & $\%$ of Positive Returns & 0.5521 & 0.5024 & 0.4753 & -2.2202 & ** & 0.5886 & 0.4979 & 0.4989 & 0.4767 & -2.5045 & ** \\
\hline \multirow[t]{2}{*}{ Oslo, Norway } & Return Mean & 0.1156 & 0.0881 & 0.0339 & -0.7420 & & 0.1467 & 0.1365 & 0.0456 & 0.0221 & -0.8029 & \\
\hline & $\%$ of Positive Returns & 0.6040 & 0.5194 & 0.5315 & -1.3781 & & 0.6222 & 0.5319 & 0.5251 & 0.5260 & -1.2655 & \\
\hline \multirow[t]{2}{*}{ Paris, France } & Return Mean & 0.1691 & -0.0102 & -0.0325 & -2.9653 & $* * *$ & 0.2396 & 0.0445 & -0.0404 & -0.0306 & -2.7641 & $* * *$ \\
\hline & $\%$ of Positive Returns & 0.5870 & 0.5042 & 0.4829 & -2.7032 & $2 * * *$ & 0.6619 & 0.5208 & 0.4861 & 0.4807 & -3.3143 & $* * *$ \\
\hline \multirow[t]{2}{*}{ Rio de Janeiro, Brazil } & Return Mean & 0.7981 & 0.6335 & 0.7728 & -0.0789 & & 0.6247 & 0.7723 & 0.6212 & 0.7795 & 0.2181 & \\
\hline & $\%$ of Positive Returns & 0.5526 & 0.5667 & 0.5679 & 0.3559 & & 0.5106 & 0.5551 & 0.5841 & 0.5400 & 0.3696 & \\
\hline \multirow[t]{2}{*}{ Santiago, Chile } & Return Mean & 0.0489 & 0.0889 & 0.0720 & 0.4207 & & 0.0627 & 0.0795 & 0.0925 & 0.0465 & -0.2434 & \\
\hline & $\%$ of Positive Returns & 0.5000 & 0.5139 & 0.4756 & -0.6546 & & 0.5128 & 0.5252 & 0.5000 & 0.4588 & -1.1182 & \\
\hline \multirow[t]{2}{*}{ Vienna, Austria } & Return Mean & 0.2813 & 0.0326 & 0.0140 & -2.4524 & $4 * *$ & 0.5796 & 0.1330 & -0.0057 & -0.0285 & -2.6995 & $* * *$ \\
\hline & $\%$ of Positive Returns & 0.5714 & 0.5327 & 0.5052 & -1.0650 & & 0.6800 & 0.5683 & 0.5110 & 0.4834 & -2.0342 & ** \\
\hline \multirow[t]{2}{*}{ Zurich, Switzerland } & Return Mean & 0.1880 & 0.0472 & 0.0111 & -2.9456 & $6 * * *$ & 0.1974 & 0.0991 & 0.0208 & 0.0027 & -1.9647 & ** \\
\hline & $\%$ of Positive Returns & 0.6517 & 0.5450 & 0.5301 & -2.9333 & $* * *$ & 0.5974 & 0.5899 & 0.5306 & 0.5280 & -1.1169 & \\
\hline U.S. CRSP-EW with & Return Mean & 0.1336 & 0.0717 & 0.0931 & -1.4335 & & 0.2233 & 0.1010 & 0.0555 & 0.1173 & -2.0767 & ** \\
\hline Other Indices & $\%$ of Positive Returns & 0.5700 & 0.5280 & 0.5175 & -3.6197 & $7 * * *$ & 0.6311 & 0.5477 & 0.5175 & 0.5175 & -4.4281 & $* * *$ \\
\hline U.S. CRSP-VW with & Return Mean & 0.1287 & 0.0707 & 0.0908 & -1.3336 & & 0.2274 & 0.0985 & 0.0545 & 0.1149 & -2.2012 & ** \\
\hline Other Indices & $\%$ of Positive Returns & 0.5644 & 0.5249 & 0.5133 & -3.5118 & $3 * * *$ & 0.6311 & 0.5428 & 0.5145 & 0.5134 & -4.5891 & $* * *$ \\
\hline
\end{tabular}

Notes:

1. $z_{-}$score ${ }_{k, 1}^{\text {mean }}=\left(\mu_{k}-\mu_{1}\right) / \sqrt{\frac{\sigma_{k}^{2}}{n_{k}}+\frac{\sigma_{1}^{2}}{n_{1}}}$ and $z_{-}$score ${\underset{k}{k, 1}}_{\text {frequence }}=\left(p_{k}-p_{1}\right) / \sqrt{\frac{p_{k}\left(1-p_{k}\right)}{n_{k}}+\frac{p_{1}\left(1-p_{1}\right)}{n_{1}}}$, where $\mu_{i}$ and $\sigma_{i}$ are the return mean and standard deviation for bin $i ; p_{i}$ is the percentage of positive returns in bin $i$; $n_{i}$ is the number of observations in bin $i$ for each statistic.

2. The asterisks ${ }^{*},{ }^{* *}$, and ${ }^{* * *}$ indicate statistical significance at the $10 \%, 5 \%$ and $1 \%$ levels, respectively (two-sided test).

3. The common sample period is from 1988 to 1997 and the matched number of observations is 1509 . 
Table 4: Regression Analysis with Monday Dummy, Tax-Dummy and Temperature

\begin{tabular}{|c|c|c|c|c|c|c|c|c|c|c|c|}
\hline & \multicolumn{5}{|c|}{ Panel A: Individual Regression with Full-Sized Sample } & \multicolumn{6}{|c|}{ Panel B: SUR Test of Equal-Sized Sample with CRSP-EW } \\
\hline & \multicolumn{5}{|c|}{$r_{t}=\alpha_{1}+\alpha_{2} r_{t-1}+\alpha_{3} D_{t}{ }^{M o n}+\alpha_{4} D_{t}{ }^{T a x}+\alpha_{5} \operatorname{Temp}_{t}+\varepsilon_{\mathrm{t}}$} & & & & & & \\
\hline & $\alpha_{2}$ & $\alpha_{3}$ & $\alpha_{4}$ & $\alpha_{5}$ & $R^{2}$ & $\alpha_{2}$ & $\alpha_{3}$ & $\alpha_{4}$ & $\alpha_{5}$ & $\alpha^{\prime}$ & $R^{2}$ \\
\hline U.S. CRSP-EW & $\begin{array}{r}0.3809 \\
40.0903\end{array}$ & $\begin{array}{c}-0.3054 \\
-18.7260\end{array}$ & 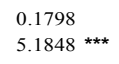 & $\begin{array}{l}-0.0021 \\
-3.0669\end{array}$ & 0.1723 & $\begin{array}{r}0.1821 \\
11.5868\end{array}$ & $\begin{array}{l}-0.2180 \\
-6.9750 \text { *** }\end{array}$ & $\begin{array}{l}0.0793 \\
1.3290\end{array}$ & $\begin{array}{l}-0.0019 \\
-1.7113\end{array}$ * & $\begin{array}{l}-0.0030 \\
-2.3795\end{array}$ ** & 0.0914 \\
\hline U.S. CRSP-VW & $\begin{array}{r}0.1713 \\
16.9216\end{array}$ & 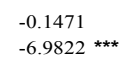 & $\begin{array}{l}0.0350 \\
0.7822\end{array}$ & $\begin{array}{l}-0.0016 \\
-1.7319\end{array}$ * & 0.0344 & & & & & & \\
\hline Canada & $\begin{array}{r}0.1900 \\
15.1222\end{array}$ & $\begin{array}{l}-0.1327 \\
-4.8211\end{array}$ & $\begin{array}{l}-0.0165 \\
-0.2894\end{array}$ & $\begin{array}{l}-0.0014 \\
-1.3369\end{array}$ & 0.0394 & $\begin{array}{l}0.1169 \\
6.9112\end{array}$ & $\begin{array}{l}-0.0296 \\
-0.7475\end{array}$ & $\begin{array}{l}-0.0272 \\
-0.3450\end{array}$ & $\begin{array}{l}-0.0017 \\
-1.2564\end{array}$ & $\begin{array}{l}-0.0030 \\
-2.1041\end{array}$ ** & 0.0353 \\
\hline Britain & $\begin{array}{l}0.0725 \\
4.7544\end{array}$ & $\begin{array}{l}-0.1080 \\
-2.8099\end{array}$ *** & $\begin{array}{l}0.0086 \\
0.1081\end{array}$ & $\begin{array}{l}-0.0051 \\
-1.9127\end{array}$ * & 0.0079 & $\begin{array}{l}0.0022 \\
0.1294\end{array}$ & $\begin{array}{l}-0.0831 \\
-1.6321\end{array}$ & $\begin{array}{l}0.0345 \\
0.4846\end{array}$ & $\begin{array}{l}-0.0024 \\
-0.8244\end{array}$ & $\begin{array}{l}-0.0048 \\
-1.4676\end{array}$ & 0.0060 \\
\hline Germany & $\begin{array}{l}0.0418 \\
3.7201\end{array}$ & $\begin{array}{l}-0.1408 \\
-4.4329 * * *\end{array}$ & $\begin{array}{l}0.0575 \\
0.8647\end{array}$ & $\begin{array}{l}-0.0037 \\
-2.1243\end{array}$ ** & 0.0050 & $\begin{array}{l}-0.0175 \\
-1.0568\end{array}$ & $\begin{array}{l}-0.0269 \\
-0.3749\end{array}$ & $\begin{array}{l}-0.1104 \\
-0.9041\end{array}$ & $\begin{array}{l}-0.0038 \\
-1.2001\end{array}$ & $\begin{array}{l}-0.0072 \\
-1.9836\end{array}$ ** & 0.0033 \\
\hline Sweden & $\begin{array}{l}0.0615 \\
3.4503\end{array}$ & $\begin{array}{l}0.0380 \\
0.5928\end{array}$ & $\begin{array}{l}0.0462 \\
0.3409\end{array}$ & $\begin{array}{l}-0.0077 \\
-2.2936\end{array}$ ** & 0.0060 & $\begin{array}{l}-0.0101 \\
-0.6064\end{array}$ & $\begin{array}{l}-0.0477 \\
-0.6318\end{array}$ & $\begin{array}{l}0.0903 \\
0.6802\end{array}$ & $\begin{array}{l}-0.0071 \\
-2.2073\end{array}$ ** & $\begin{array}{l}-0.0081 \\
-2.2252\end{array}$ ** & 0.0079 \\
\hline Australia & $\begin{array}{l}0.0849 \\
5.4867\end{array}$ & $\begin{array}{l}-0.0491 \\
-1.2330\end{array}$ & $\begin{array}{l}0.1755 \\
2.1635 \text { ** }\end{array}$ & $\begin{array}{l}0.0011 \\
0.2700\end{array}$ & 0.0089 & $\begin{array}{l}0.0254 \\
1.3576\end{array}$ & $\begin{array}{l}-0.0449 \\
-0.9203\end{array}$ & $\begin{array}{l}0.0412 \\
0.5009\end{array}$ & $\begin{array}{l}-0.0051 \\
-1.2224\end{array}$ & $\begin{array}{l}-0.0043 \\
-0.9532\end{array}$ & 0.0024 \\
\hline Japan & $\begin{array}{l}0.0039 \\
0.2537\end{array}$ & $\begin{array}{l}-0.1195 \\
-2.2788 \text { ** }\end{array}$ & $\begin{array}{l}-0.0906 \\
-0.7475\end{array}$ & $\begin{array}{l}-0.0047 \\
-1.7409\end{array}$ * & 0.0019 & $\begin{array}{l}-0.0029 \\
-0.1508\end{array}$ & $\begin{array}{l}-0.2719 \\
-3.2035\end{array}$ & $\begin{array}{l}-0.0051 \\
-0.0306\end{array}$ & $\begin{array}{l}0.0009 \\
0.2295\end{array}$ & $\begin{array}{l}-0.0033 \\
-0.7821\end{array}$ & 0.0052 \\
\hline Taiwan & $\begin{array}{l}0.1003 \\
8.1519\end{array}$ & $\begin{array}{l}-0.1263 \\
-2.2780\end{array}$ ** & $\begin{array}{l}0.0075 \\
0.0655\end{array}$ & $\begin{array}{l}-0.0074 \\
-1.9177^{*}\end{array}$ & 0.0114 & $\begin{array}{l}-0.0083 \\
-0.4005\end{array}$ & $\begin{array}{l}-0.0122 \\
-0.1073\end{array}$ & $\begin{array}{l}-0.3169 \\
-1.3270\end{array}$ & $\begin{array}{l}-0.0276 \\
-3.4631\end{array}$ *** & $\begin{array}{l}-0.0292 \\
-3.6295\end{array}$ *** & 0.0062 \\
\hline $\begin{array}{l}\text { System-wide } R^{2} \\
\chi^{2}(8)\end{array}$ & & & & & & & & & $\begin{array}{c}0.0140 \\
22.0509 \text { ^^^ }\end{array}$ & & \\
\hline$\chi^{2}(7)$ & & & & & & & & & $15.4249 \wedge \wedge$ & & \\
\hline
\end{tabular}

Notes:

1. This table reports regressions analysis of both the full sample OLS regression and the equal-size sample SUR (Seemingly Unrelated Regression). We control for first order auto-correlation $\left(r_{t-1}\right)$, the Monday effect $\left(D_{t}^{M o n}\right)$, and the tax-loss effect $\left(D_{t}^{\text {Tax }}\right)$. The tax dummy $\left(D_{t}^{\text {Tax }}\right)$ covers the first 10 trading days of the taxation year. The taxation year starts on April 6 in Britain, July in Australia, and January 1 in all other jurisdictions.

2. For each market, the first row contains the parameter estimates, the second contains the t-values. For brevity and clarity, we omit the intercept estimate and only indicate the significance for explanatory variables $D_{t}^{M o n}, D_{t}^{T a x}$, and Temp . The last column of each panel contains the $R^{2}$ of individual OLS regressions. The system-wide $R^{2}$ is for SUR.

3. The column with heading $\alpha^{\prime}$ contains the coefficients and t-values of the temperature variables Temp from individual regressions using the equal-size sample.

4. The asterisks ${ }^{*},{ }^{* *}$, and ${ }^{* * *}$ indicate statistical significance at the $10 \%, 5 \%$ and $1 \%$ levels respectively (two-sided test). The chi-square statistic with 8 degrees of freedom is for testing if all coefficients for each explanatory variable are equal to zero. The second chi-square statistic with 7

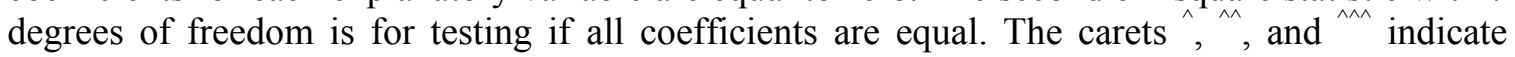
statistical significance at the $10 \%, 5 \%$ and $1 \%$ levels respectively.

5. The common sample period is from 1989 to 1999 and the number of observations is 2252 . 
Table 5: SUR and Related Tests for Expanded Sample with Equal Size

\begin{tabular}{|c|c|c|c|c|c|c|c|c|c|c|}
\hline & \multirow{2}{*}{\multicolumn{2}{|c|}{ Panel A: Cloud Cover }} & \multicolumn{8}{|c|}{$r_{t}=\alpha_{1}+\alpha_{2} r_{t-1}+\alpha_{3} D_{t}^{\text {Mon }}+\alpha_{4} D_{t}^{\text {Tax }}+\alpha_{5}$ Temp $_{t}+\alpha_{6}$ Cloud $_{\mathrm{t}}+\alpha_{7}$ SAD $_{\mathrm{t}}+\varepsilon_{\mathrm{t}}$} \\
\hline & & & \multicolumn{3}{|c|}{ Panel B: SUR with CRSP-VW } & \multicolumn{5}{|c|}{ Panel C: Individual Test } \\
\hline & Mean & Std. Dev. & Temp ${ }_{t}$ & Cloud $t_{t}$ & $S A D_{t}$ & Temp ${ }_{t}$ & Cloud $_{t}$ & $S A D_{t}$ & & $R^{2}$ \\
\hline \multirow[t]{2}{*}{ New York, U.S. CRSP-VW } & 4.749 & 2.734 & -0.0015 & -0.0016 & 0.0331 & -0.0024 & -0.0080 & 0.0148 & & 0.0108 \\
\hline & & & -0.6120 & -0.2063 & 0.5286 & -0.9344 & -0.9415 & 0.2312 & & \\
\hline \multirow[t]{2}{*}{ London, Britain } & 5.832 & 1.889 & -0.0021 & 0.0049 & 0.0391 & -0.0034 & -0.0094 & 0.0267 & & 0.0085 \\
\hline & & & -0.4810 & 0.4714 & 0.5183 & -0.6311 & -0.6591 & 0.3360 & & \\
\hline \multirow[t]{2}{*}{ Stockholm, Sweden } & 5.309 & 1.955 & -0.0026 & -0.0028 & 0.0750 & -0.0069 & -0.0019 & -0.0015 & & 0.0073 \\
\hline & & & -0.5021 & -0.1662 & 0.6667 & -1.1014 & -0.0848 & -0.0118 & & \\
\hline \multirow[t]{2}{*}{ Sydney, Australia } & 3.812 & 2.320 & -0.0219 & -0.0084 & -0.1465 & -0.0279 & -0.0035 & -0.2435 & & 0.0137 \\
\hline & & & $-3.1561 * * *$ & -0.9234 & -1.6381 & $-3.0909 * * *$ & -0.2947 & -2.2378 & ** & \\
\hline \multirow[t]{2}{*}{ Taipei, Taiwan } & 5.432 & 1.918 & -0.0429 & 0.0005 & 0.0863 & -0.0439 & 0.0092 & 0.0909 & & 0.0151 \\
\hline & & & $-3.0882 * * *$ & 0.0124 & 0.4518 & $-3.0859 * * *$ & 0.2387 & 0.4692 & & \\
\hline \multirow[t]{2}{*}{ Amsterdam, Netherlands } & 5.434 & 2.239 & -0.0086 & 0.0024 & -0.1025 & -0.0136 & -0.0104 & -0.1570 & & 0.0120 \\
\hline & & & $-2.4431 * *$ & 0.3593 & -1.5935 & $-2.8576 * * *$ & -0.9146 & -2.1878 & $* *$ & \\
\hline \multirow[t]{2}{*}{ Athens, Greece } & 3.431 & 2.592 & -0.0029 & -0.0339 & -0.2388 & -0.0075 & -0.0417 & -0.2754 & & 0.0233 \\
\hline & & & -0.3026 & -1.4059 & -1.3328 & -0.7511 & $-1.6463 *$ & -1.5059 & & \\
\hline \multirow[t]{2}{*}{ Auckland, New Zealand } & 4.685 & 2.272 & -0.0286 & 0.0085 & -0.1468 & -0.0352 & 0.0157 & -0.2907 & & 0.0142 \\
\hline & & & $-2.7955^{* * *}$ & 0.6818 & -1.1892 & $-2.7920 * * *$ & 1.0070 & -2.0269 & ** & \\
\hline \multirow[t]{2}{*}{ Buenos Aires, Argentina } & 4.152 & 2.774 & -0.0147 & 0.1112 & -0.1977 & -0.0077 & 0.1093 & -0.1122 & & 0.0231 \\
\hline & & & -0.5650 & $2.3893 * *$ & -0.4401 & -0.2909 & $2.2956 * *$ & -0.2454 & & \\
\hline \multirow[t]{2}{*}{ Copenhagen, Demark } & 5.362 & 2.199 & 0.0014 & 0.0189 & 0.1266 & -0.0017 & 0.0240 & 0.0836 & & 0.0244 \\
\hline & & & 0.3446 & 1.8282 * & 1.8034 * & -0.3635 & 1.9171 * & 1.0762 & & \\
\hline \multirow[t]{2}{*}{ Dublin, Ireland } & 5.904 & 1.829 & -0.0070 & -0.0033 & -0.0119 & -0.0119 & -0.0148 & -0.0437 & & 0.0126 \\
\hline & & & -1.0716 & -0.2430 & -0.1460 & -1.5559 & -0.8954 & -0.4918 & & \\
\hline \multirow[t]{2}{*}{ Helsinki, Finland } & 5.533 & 2.330 & -0.0026 & -0.0104 & 0.1450 & -0.0046 & -0.0162 & 0.1138 & & 0.0317 \\
\hline & & & -0.5868 & -0.7846 & 1.4812 & -0.9374 & -1.0501 & 1.0837 & & \\
\hline \multirow[t]{2}{*}{ Istanbul, Turkey } & 3.921 & 2.576 & 0.0011 & -0.0086 & 0.0332 & -0.0014 & -0.0052 & 0.0092 & & 0.0201 \\
\hline & & & 0.0924 & -0.2736 & 0.1465 & -0.1237 & -0.1599 & 0.0401 & & \\
\hline \multirow[t]{2}{*}{ Johannesburg, South Africa } & 3.061 & 2.420 & -0.0022 & -0.0124 & -0.2245 & -0.0060 & -0.0010 & -0.3176 & & 0.0194 \\
\hline & & & -0.2571 & -0.9386 & $-1.9471 *$ & -0.6185 & -0.0650 & -2.5351 & ** & \\
\hline \multirow[t]{2}{*}{ Kuala Lumpur, Malaysia } & 6.866 & 0.352 & -0.0066 & 0.0684 & 0.0437 & 0.0103 & 0.0825 & 0.0236 & & 0.0190 \\
\hline & & & -0.1704 & 0.7752 & 0.4049 & 0.2349 & 0.8202 & 0.2040 & & \\
\hline
\end{tabular}


Table 5: SUR and Related Tests for Expanded Sample with Equal Size

... Continued

\begin{tabular}{|c|c|c|c|c|c|c|c|c|c|}
\hline & \multirow{2}{*}{\multicolumn{2}{|c|}{ Panel A: Cloud Cover }} & \multicolumn{7}{|c|}{$r_{t}=\alpha_{1}+\alpha_{2} r_{t-1}+\alpha_{3} D_{t}{ }^{\text {Mon }}+\alpha_{4} D_{t}^{\text {Tax }}+\alpha_{5}$ Temp $_{t}+\alpha_{6}$ Cloud $_{\mathrm{t}}+\alpha_{7} S A D_{\mathrm{t}}+\varepsilon_{\mathrm{t}}$} \\
\hline & & & \multicolumn{3}{|c|}{ Panel B: SUR with CRSP-VW } & \multicolumn{4}{|c|}{ Panel C: Individual Test } \\
\hline & Mean & Std. Dev. & Temp , & Cloud $t_{1}$ & $S A D t_{t}$ & Temp $t$ & 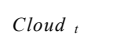 & $S A D{ }_{t}$ & $R^{2}$ \\
\hline \multirow[t]{2}{*}{ Madrid, Spain } & 3.597 & 2.621 & -0.0023 & 0.0188 & 0.0938 & -0.0058 & 0.0213 & 0.0444 & 0.0116 \\
\hline & & & -0.6054 & 2.0446 ** & 1.1016 & -1.1929 & 1.6365 & 0.4677 & \\
\hline \multirow[t]{2}{*}{ Manila, Philippines } & 5.312 & 2.055 & -0.0043 & 0.0149 & -0.0061 & -0.0140 & 0.0072 & -0.0239 & 0.0465 \\
\hline & & & -0.1575 & 0.6418 & -0.0436 & -0.4873 & 0.2960 & -0.1649 & \\
\hline \multirow[t]{2}{*}{ Milan, Italy } & 4.102 & 2.792 & -0.0032 & 0.0128 & 0.0573 & -0.0058 & 0.0235 & 0.0166 & 0.0231 \\
\hline & & & -0.6560 & 1.1162 & 0.5342 & -1.0670 & 1.7209 * & 0.1452 & \\
\hline \multirow[t]{2}{*}{ Oslo, Norway } & 5.439 & 2.256 & -0.0035 & -0.0033 & -0.1348 & -0.0063 & 0.0137 & -0.1928 & 0.0178 \\
\hline & & & -0.6937 & -0.2151 & -1.1523 & -1.0545 & 0.7098 & -1.5059 & \\
\hline \multirow[t]{2}{*}{ Paris, France } & 5.294 & 2.298 & -0.0073 & -0.0097 & -0.0032 & -0.0133 & -0.0261 & -0.0581 & 0.0141 \\
\hline & & & $-1.8226 *$ & -1.1849 & -0.0390 & $-2.5643 * *$ & $-2.0224 * *$ & -0.6641 & \\
\hline \multirow[t]{2}{*}{ Santiago, Chile } & 3.099 & 3.065 & -0.0029 & 0.0049 & -0.1974 & -0.0019 & 0.0042 & -0.2099 & 0.0863 \\
\hline & & & -0.4460 & 0.6366 & $-2.2846 * *$ & -0.2754 & 0.5327 & $-2.3655 * *$ & \\
\hline \multirow[t]{2}{*}{ Vienna, Austria } & 5.076 & 2.459 & -0.0023 & -0.0137 & 0.0345 & -0.0084 & -0.0094 & -0.0448 & 0.0600 \\
\hline & & & -0.5084 & -1.2007 & 0.3723 & -1.6223 & -0.6803 & -0.4473 & \\
\hline \multirow[t]{2}{*}{ Zurich, Switzerland } & 5.283 & 2.465 & -0.0052 & -0.0077 & 0.0145 & -0.0098 & -0.0088 & -0.0326 & 0.0116 \\
\hline & & & -1.5076 & -1.1072 & 0.2034 & $-2.1207 * *$ & -0.7984 & -0.4141 & \\
\hline System-wide $\quad R^{2}$ & & & & & 0.0251 & & & & \\
\hline$\chi^{2}(23)$ & & & $35.8773 \wedge$ & 25.3794 & 31.7398 & & & & \\
\hline$\chi^{2}(22)$ & & & $33.5255^{\wedge}$ & $32.8806^{\wedge}$ & 30.2556 & & & & \\
\hline
\end{tabular}

Notes:

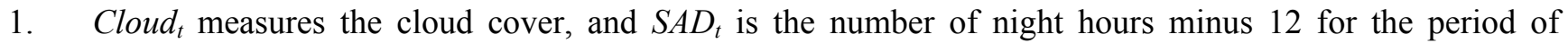
September 21 to March 20, and zero otherwise; The number of night hours is calculated as $7.72 \cdot \operatorname{arcos}[-$ $\left.\tan (2 \pi \delta / 360) \tan \left(\lambda_{t}\right)\right]$ for the Southern Hemisphere, and 24 minus this quantity for the Northern Hemisphere. In the above, $\delta$ is the latitude of the market location, and $\lambda_{t}=0.4102 \cdot \sin [(2 \pi / 365)$ (julian80.25)] where "julian" represents the day of the year, i.e., julian=1 for January 1, 2 for January 2, and so on. The equal-size sample is from 1989 to 1997 with the matched number of observations is 1013 .

2. For brevity and clarity, we only report the coefficients and $t$-values for $\operatorname{Temp}_{t}$, Clould $_{t}$, and $S A D_{t}$. The $\operatorname{asterisks}^{*},{ }^{* *}$, and ${ }^{* * *}$ indicate statistical significance at the $10 \%, 5 \%$ and $1 \%$ levels respectively (twosided test).

3. The tax dummy, $D_{t}^{T a x}$ covers the first ten trading days of the taxation year. The taxation year starts on April 6 in Britain, July1 in Australia, and January 1 in all other jurisdictions.

4. The chi-square statistic with 23 degrees of freedom is for testing if all coefficients for each explanatory variable are equal to zero. The second chi-square statistic with 22 degrees of freedom is for testing if all coefficients are equal. The carets ${ }^{\wedge},{ }^{\wedge}$, and ${ }^{\wedge}$ indicate statistical significance at the $10 \%, 5 \%$ and $1 \%$ levels respectively.

5. The common sample period is from 1989 to 1997 and the number of observations is 1013 . 
Table 6: Nonparametric Tests for Correlation and Temperature Level Effect

Panel A: Spearman's Rank Correlation between Temperature and Returns

\begin{tabular}{|c|c|c|c|c|c|c|c|c|c|c|c|c|}
\hline & \multicolumn{12}{|c|}{ Number of Temperature Bins } \\
\hline & 30 & & 40 & & 50 & & 60 & & 70 & & 100 & \\
\hline U.S. CSRP-EW & -0.6329 & *** & -0.6583 & *** & -0.6268 & $* * *$ & -0.5763 & $* * *$ & -0.5512 & $* * *$ & -0.5343 & $* * *$ \\
\hline U.S. CSRP-VW & -0.4679 & *** & -0.3878 & $* * *$ & -0.3817 & $* * *$ & -0.3429 & $\star * \star *$ & -0.3201 & $* * *$ & -0.2216 & ** \\
\hline Canada & -0.4492 & ** & -0.3302 & ** & -0.2976 & ** & -0.2545 & ** & -0.2933 & ** & -0.2044 & ** \\
\hline Britain & -0.2801 & & -0.2750 & * & -0.2905 & ** & -0.2636 & ** & -0.1910 & & -0.1585 & \\
\hline Germany & -0.3811 & ** & -0.2790 & * & -0.3047 & ** & -0.2326 & * & -0.2370 & ** & -0.2474 & ** \\
\hline Sweden & -0.3366 & * & -0.3771 & ** & -0.2547 & * & -0.3138 & ** & -0.2698 & ** & -0.2012 & ** \\
\hline Australia & -0.1417 & & -0.1064 & & -0.0805 & & -0.0736 & & -0.0781 & & -0.0683 & \\
\hline Japan & -0.3531 & * & -0.2949 & * & -0.2887 & ** & -0.2442 & * & -0.2932 & $* *$ & -0.2019 & ** \\
\hline Taiwan & -0.4723 & $* \star *$ & -0.3792 & ** & -0.3484 & ** & -0.3268 & $* * *$ & -0.2876 & $* *$ & -0.2602 & *** \\
\hline CRSP-EW \& all others & -0.4616 & ** & -0.4443 & $* * *$ & -0.4138 & $* * *$ & -0.3982 & $* \star *$ & -0.3160 & $* * *$ & -0.2950 & *** \\
\hline CRSP-VW \& all others & -0.2627 & & -0.3004 & * & -0.2791 & ** & -0.2362 & * & -0.2377 & ** & -0.2235 & ** \\
\hline
\end{tabular}

Panel B: Chi-square Statistics for Friedman's Test

\begin{tabular}{|c|c|c|c|c|}
\hline $\begin{array}{c}\text { Number of } \\
\text { Temperature } \\
\text { B ins }\end{array}$ & $\begin{array}{c}\text { CRSP-EW } \\
\text { and all O ther } \\
\text { Indices } \\
\end{array}$ & & $\begin{array}{c}\text { C R S P -V W } \\
\text { and all Other } \\
\text { Indices } \\
\end{array}$ & \\
\hline 2 & 5.5000 & $\wedge \wedge$ & 5.6667 & $\wedge \wedge$ \\
\hline 3 & 6.1111 & $\wedge \wedge$ & 5.2222 & $\wedge$ \\
\hline 4 & 8.5833 & $\wedge \wedge$ & 9.1667 & $\wedge \wedge$ \\
\hline 5 & 9.6000 & $\wedge \wedge$ & 7.9333 & $\wedge$ \\
\hline
\end{tabular}

Notes:

1. Spearman's rank correlation is calculated based on the average temperature and return of each temperature bin. Please see the text for details. The asterisks ${ }^{*},{ }^{* *}$, and ${ }^{* * *}$ indicate statistical significance at the $10 \%, 5 \%$ and $1 \%$ levels, respectively (two-sided test).

2. Friedman's two-way analysis of variance is used to test the temperature level effect. The test helps to determine if investors around the globe exhibit a uniform investment behavior within the same temperature range. The carets ${ }^{\wedge}, \wedge$, and ${ }^{\wedge}$ indicate statistical significance of the chi-square statistics at the $10 \%, 5 \%$, and $1 \%$ levels, respectively. 
Table 7: Temperature Deviation Test with the Equal-Size Sample

\begin{tabular}{|c|c|c|c|c|c|c|c|c|c|c|}
\hline & $\begin{array}{l}\text { 0-day } M W \\
\text { Temp Dev }_{\mathrm{t}}\end{array}$ & $R^{2}$ & $\begin{array}{l}\text { 3-day } M W \\
\text { Temp Dev }_{\mathrm{t}}\end{array}$ & $R^{2}$ & $\begin{array}{l}\text { 7-day } M W \\
\text { Temp Dev }_{\mathrm{t}}\end{array}$ & $R^{2}$ & $\begin{array}{l}\text { 15-day } M W \\
\text { Temp Dev }\end{array}$ & $R^{2}$ & $\begin{array}{l}\text { 31-day } M W \\
\text { Temp Dev }\end{array}$ & $R^{2}$ \\
\hline U.S. CRSP-EW & $\begin{array}{l}-0.00044 \\
-1.88048 \text { * }\end{array}$ & 0.0950 & $\begin{array}{l}-0.00041 \\
-1.76797 \text { * }\end{array}$ & 0.0994 & $\begin{array}{l}-0.00041 \\
-1.75766 \text { * }\end{array}$ & 0.1035 & $\begin{array}{l}-0.00042 \\
-1.89810 \text { * }\end{array}$ & 0.0880 & $\begin{array}{l}-0.00039 \\
-1.76232 \text { * }\end{array}$ & 0.0909 \\
\hline U.S. CRSP-VW & $\begin{array}{l}-0.00048 \\
-1.42707\end{array}$ & 0.0089 & $\begin{array}{l}-0.00045 \\
-1.32952\end{array}$ & 0.0092 & $\begin{array}{l}-0.00046 \\
-1.36794\end{array}$ & 0.0107 & $\begin{array}{l}-0.00056 \\
-1.77095 \text { * }\end{array}$ & 0.0083 & $\begin{array}{l}-0.00047 \\
-1.44533\end{array}$ & 0.0076 \\
\hline Canada & $\begin{array}{l}-0.00036 \\
-1.26418\end{array}$ & 0.0295 & $\begin{array}{l}-0.00032 \\
-1.13381\end{array}$ & 0.0306 & $\begin{array}{l}-0.00031 \\
-1.12833\end{array}$ & 0.0371 & $\begin{array}{l}-0.00032 \\
-1.24374\end{array}$ & 0.0465 & $\begin{array}{l}-0.00033 \\
-1.22541\end{array}$ & 0.0407 \\
\hline Britain & $\begin{array}{l}-0.00052 \\
-1.00194\end{array}$ & 0.0068 & $\begin{array}{l}-0.00054 \\
-1.06361\end{array}$ & 0.0098 & $\begin{array}{l}-0.00054 \\
-1.06048\end{array}$ & 0.0087 & $\begin{array}{l}-0.00053 \\
-1.11128\end{array}$ & 0.0059 & $\begin{array}{l}-0.00053 \\
-1.04470\end{array}$ & 0.0082 \\
\hline Germany & $\begin{array}{l}-0.00052 \\
-0.82440\end{array}$ & 0.0043 & $\begin{array}{l}-0.00052 \\
-0.82889\end{array}$ & 0.0047 & $\begin{array}{l}-0.00053 \\
-0.84209\end{array}$ & 0.0049 & $\begin{array}{l}-0.00031 \\
-0.52593\end{array}$ & 0.0050 & $\begin{array}{l}-0.00052 \\
-0.84773\end{array}$ & 0.0064 \\
\hline Sweden & $\begin{array}{l}-0.00031 \\
-0.48429\end{array}$ & 0.0030 & $\begin{array}{l}-0.00044 \\
-0.69038\end{array}$ & 0.0051 & $\begin{array}{l}-0.00063 \\
-0.99010\end{array}$ & 0.0065 & $\begin{array}{l}-0.00034 \\
-0.55604\end{array}$ & 0.0055 & $\begin{array}{l}-0.00061 \\
-0.97066\end{array}$ & 0.0046 \\
\hline Australia & $\begin{array}{l}-0.00002 \\
-0.15059\end{array}$ & 0.0014 & $\begin{array}{l}-0.00002 \\
-0.16027\end{array}$ & 0.0014 & $\begin{array}{l}-0.00003 \\
-0.19735\end{array}$ & 0.0014 & $\begin{array}{l}-0.00002 \\
-0.13186\end{array}$ & 0.0010 & $\begin{array}{l}-0.00002 \\
-0.17065\end{array}$ & 0.0015 \\
\hline Japan & $\begin{array}{l}-0.00044 \\
-0.40343\end{array}$ & 0.0057 & $\begin{array}{l}-0.00066 \\
-0.60249\end{array}$ & 0.0061 & $\begin{array}{l}-0.00064 \\
-0.60567\end{array}$ & 0.0057 & $\begin{array}{l}0.00014 \\
0.15232\end{array}$ & 0.0064 & $\begin{array}{l}-0.00068 \\
-0.65273\end{array}$ & 0.0055 \\
\hline Taiwan & $\begin{array}{l}-0.00526 \\
-3.59446\end{array}$ *** & 0.0123 & $\begin{array}{l}-0.00491 \\
-3.41922\end{array}$ *** & 0.0104 & $\begin{array}{l}-0.00470 \\
-3.27036\end{array}$ *** & 0.0094 & $\begin{array}{l}-0.00406 \\
-2.97286\end{array}$ & 0.0102 & $\begin{array}{l}-0.00475 \\
-3.35219 \text { *** }\end{array}$ & 0.0102 \\
\hline
\end{tabular}

Notes:

1. For brevity, we only report the coefficients and the t-values for temperature deviations together with $R^{2}$ of the regressions.

2. The explanatory variable " $k$-day MW Temp $\operatorname{Dev}_{t}$ " $(k=0,3,7,15$, and 31$)$ is the deviation of daily temperature from a moving window average of historical daily temperatures. The moving window symmetrically straddles the current day and $\mathrm{k}$ is the number of days used to calculate the moving average.

3. The asterisks ${ }^{*},{ }^{* *}$, and ${ }^{* * *}$ indicate statistical significance at the $10 \%, 5 \%$ and $1 \%$ levels respectively (two-sided test) for the explanatory variable " $k$-day $M W$ Temp Dev ${ }_{t}$ ".

4. The tax dummy covers the first ten trading days of the taxation year. The taxation year starts on April 6 in Britain, July1 in Australia, and January 1 in all other jurisdictions. 
Table 8: Aggregate Bin Test and Regression Analysis for the U.S. CRSP Index

Panel A : Bin Test

\begin{tabular}{|c|c|c|c|c|c|c|c|c|c|c|c|c|}
\hline & \multicolumn{4}{|c|}{$\#$ of bins $=3$} & & \multicolumn{5}{|c|}{$\#$ of bins $=4$} & \\
\hline & & bin 1 & bin 2 & bin 3 & z-score $(3,1)$ & & bin 1 & bin 2 & bin 3 & bin 4 & z-score $(4,1)$ & \\
\hline CRSP-EW & Return Mean & 0.2273 & 0.0982 & 0.0613 & -4.7369 & $* * *$ & 0.2030 & 0.1490 & 0.0669 & 0.0579 & -2.6317 & $* * *$ \\
\hline \multirow[t]{2}{*}{ TEMP-EW } & Std. Dev. of Return & 0.5928 & 0.7038 & 0.5020 & & & 0.5779 & 0.5696 & 0.7291 & 0.5099 & & \\
\hline & $\%$ of Positive Returns & 0.7103 & 0.6289 & 0.6163 & -3.3941 & $* * *$ & 0.7265 & 0.6432 & 0.6241 & 0.6155 & -2.5704 & $* *$ \\
\hline CRSP-EW & Return Mean & 0.2552 & 0.0930 & 0.0617 & -5.6465 & *** & 0.2058 & 0.1497 & 0.0676 & 0.0570 & -2.7380 & $* * *$ \\
\hline \multirow[t]{2}{*}{ TEMP-PW } & Std. Dev. of Return & 0.5719 & 0.7037 & 0.5015 & & & 0.5806 & 0.5533 & 0.7306 & 0.5153 & & \\
\hline & $\%$ of Positive Returns & 0.7429 & 0.6229 & 0.6169 & -4.6493 & $* * *$ & 0.7049 & 0.6515 & 0.6207 & 0.6137 & -2.1061 & $* *$ \\
\hline CRSP-VW & Return Mean & 0.1517 & 0.0625 & 0.0512 & -2.0368 & ** & 0.0884 & 0.1014 & 0.0422 & 0.0530 & -0.4082 & \\
\hline \multirow[t]{2}{*}{ TEMP-EW } & Std. Dev. of Return & 0.8288 & 0.9418 & 0.7463 & & & 0.9138 & 0.7689 & 0.9890 & 0.7524 & & \\
\hline & $\%$ of Positive Returns & 0.6012 & 0.5433 & 0.5492 & -1.7549 & * & 0.5812 & 0.5555 & 0.5468 & 0.5479 & -0.7015 & \\
\hline CRSP-VW & Return Mean & 0.1774 & 0.0583 & 0.0512 & -2.5804 & $* * *$ & 0.1040 & 0.0997 & 0.0383 & 0.0578 & -0.5491 & \\
\hline \multirow[t]{2}{*}{ TEMP-PW } & Std. Dev. of Return & 0.8105 & 0.9373 & 0.7516 & & & 0.9029 & 0.7524 & 0.9895 & 0.7586 & & \\
\hline & $\%$ of Positive Returns & 0.6190 & 0.5408 & 0.5490 & -2.3575 & ** & 0.6066 & 0.5499 & 0.5448 & 0.5522 & -1.1766 & \\
\hline
\end{tabular}

Panel B: Regressions

\begin{tabular}{|c|c|c|c|c|c|c|}
\hline & $\alpha_{1}$ & $\alpha_{2}$ & $\alpha_{3}$ & $\alpha_{4}$ & $\alpha_{s}$ & $R^{2}$ \\
\hline C R S P-EW, T E M P-E W & $\begin{array}{l}0.1017 \\
9.4363\end{array}$ & $\begin{array}{r}0.3265 \\
22.0490\end{array}$ & $\begin{array}{r}-0.2911 \\
-12.7452 \quad \text { *** }\end{array}$ & $\begin{array}{l}0.1480 \\
3.0545\end{array}$ *** & $\begin{array}{l}-0.0252 \\
-2.2129\end{array}$ ** & 0.1375 \\
\hline C R S P-EW, TE M P-PW & $\begin{array}{l}0.1008 \\
9.1853\end{array}$ & $\begin{array}{r}0.3266 \\
22.0515\end{array}$ & $\begin{array}{r}-0.2911 \\
-12.7460\end{array}$ & $\begin{array}{l}0.1489 \\
3.0761 \text { *** }\end{array}$ & $\begin{array}{l}-0.0211 \\
-2.1829\end{array}$ ** & 0.1375 \\
\hline C R S P-V W, TE M P - E W & $\begin{array}{l}0.0638 \\
3.9890\end{array}$ & $\begin{array}{l}0.1206 \\
7.7299\end{array}$ & $\begin{array}{l}-0.0757 \\
-2.2471\end{array}$ ** & $\begin{array}{l}0.0096 \\
0.1340\end{array}$ & $\begin{array}{l}-0.0180 \\
-1.0661\end{array}$ & 0.0162 \\
\hline C R S P-VW, T E M P - P W & $\begin{array}{l}0.0629 \\
3.8695\end{array}$ & $\begin{array}{l}0.1206 \\
7.7300\end{array}$ & $\begin{array}{l}-0.0757 \\
-2.2476\end{array}$ ** & $\begin{array}{l}0.0098 \\
0.1373\end{array}$ & $\begin{array}{l}-0.0154 \\
-1.0727\end{array}$ & 0.0162 \\
\hline
\end{tabular}

Notes:

1. This table presents bin test and regression results for the U.S. CRSP index (equal-weighted or value-weighted) and the aggregate temperature which is either equal-weighted (TEMP-EW) or population-weighted (TEMP-PW) average of temperatures in the following cities: Atlanta, Chicago, Dallas, Los Angelas, New York, Philadelphia, and Seattle. The sample period is from January 1, 1982 to December 31, 1997.

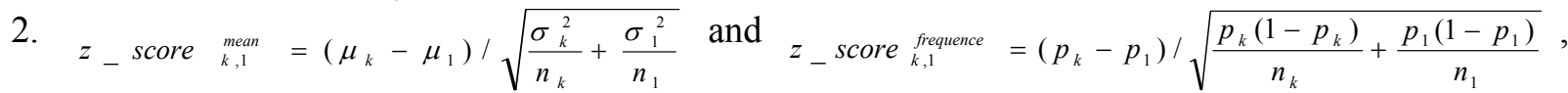
where $\mu_{i}$ and $\sigma_{l}$ are the return mean and standard deviation for bin $i ; p_{i}$ is the percentage of positive returns in bin $i ; n_{i}$ is the number of observations in bin $i$ for each statistic.

3. The asterisks ${ }^{*},{ }^{* *}$, and ${ }^{* * *}$ indicate statistical significance at the $10 \%, 5 \%$ and $1 \%$ levels, respectively (two-sided test). For the regression test, we only indicate the significance for explanatory variables $D_{t}^{M o n}, D_{t}^{T a x}$, and Temp.

4. The tax dummy covers the first ten trading days of the taxation year which starts on January 1 . 
Table 9: Regression For the Sub-Sample Periods of the U.S. CRSP index

\begin{tabular}{|c|c|c|c|c|c|c|}
\hline & \multicolumn{6}{|c|}{$r_{t}=\alpha_{1}+\alpha_{2} r_{t-1}+\alpha_{3} D_{t}^{\text {Mon }}+\alpha_{4} D_{t}^{\text {Tax }}+\alpha_{5}$ Temp $_{t}+\varepsilon_{t}$} \\
\hline & $\alpha_{1}$ & $\alpha_{2}$ & $\alpha_{3}$ & $\alpha_{4}$ & $\alpha_{5}$ & $R^{2}$ \\
\hline \multicolumn{7}{|c|}{ CRSP Equal-weighted Index } \\
\hline \multirow[t]{2}{*}{$1962-1974$} & 0.0650 & 0.4262 & -0.3249 & 0.2439 & -0.0009 & 0.2087 \\
\hline & 4.2846 & 26.3470 & $-10.7572 * * *$ & $3.7389 * * *$ & -0.7004 & \\
\hline \multirow[t]{2}{*}{$1975-1987$} & 0.0966 & 0.3722 & -0.3453 & 0.1978 & -0.0025 & 0.1706 \\
\hline & 6.8638 & 23.0726 & $-12.1044 * * *$ & $3.2673 * * *$ & $-2.0579 * *$ & \\
\hline \multirow[t]{3}{*}{$1988-1999$} & 0.1033 & 0.3015 & -0.2380 & 0.0534 & -0.0036 & 0.1162 \\
\hline & 8.5317 & 17.4744 & $-9.4430 * * *$ & 1.0055 & $-3.2776^{* * *}$ & \\
\hline & \multicolumn{4}{|c|}{ CRSP Value-weighted Index } & & \\
\hline \multirow[t]{2}{*}{$1962-1974$} & 0.0596 & 0.2861 & -0.2622 & 0.0632 & -0.0007 & 0.0993 \\
\hline & 3.7487 & 16.7847 & $-8.3144 * * *$ & 0.9310 & -0.5088 & \\
\hline \multirow[t]{2}{*}{$1975-1987$} & 0.0797 & 0.1727 & -0.1926 & 0.0958 & -0.0008 & 0.0368 \\
\hline & 4.0913 & 10.0770 & $-4.9176^{* * *}$ & 1.1518 & -0.4751 & \\
\hline \multirow[t]{2}{*}{$1988-1999$} & 0.0483 & 0.0699 & 0.0111 & -0.1347 & -0.0038 & 0.0075 \\
\hline & 2.6737 & 3.8628 & 0.2968 & $-1.7010 *$ & $-2.3486^{* *}$ & \\
\hline
\end{tabular}

Notes:

1. For each regression, the first row contains the parameter estimates, and the second row contains the $\mathrm{t}$-values. The $R^{2}$ for each regression is reported the last column.

2. The asterisks ${ }^{*},{ }^{* *}$, and ${ }^{* * *}$ indicate statistical significance at the $10 \%, 5 \%$ and $1 \%$ levels respectively (two-sided test). For clarity, we only indicate the significance for explanatory variables $D_{t}^{\text {Mon }}, D_{t}^{\text {Tax }}$, and $T e m p_{t}$.

3. The tax dummy covers the first ten trading days of the taxation year. The taxation year starts on January 1 in the U.S.. 